\title{
Ambient Noise Recorded by a Dense Broadband Seismic Deployment in Western Iberia
}

\author{
by Susana Custódio, ${ }^{*}$ Nuno A. Dias, Bento Caldeira, Fernando Carrilho, Sara \\ Carvalho, Carlos Corela, Jordi Díaz, João Narciso, Guilherme Madureira, \\ Luis Matias, Christian Haberland, and WILAS Team
}

\begin{abstract}
The West Iberia Lithosphere and Asthenosphere Structure (WILAS) project densely covered Portugal with broadband seismic stations for 2 yrs. Here we provide an overview of the deployment, and we characterize the network ambient noise and its sources. After explaining quality control, which includes the assessment of sensor orientation, we characterize the background noise in the short-period (SP), microseismic, and long-period (LP) bands. We observe daily variations of SP noise associated with anthropogenic activity. Temporary and permanent stations present very similar noise levels at all periods, except at horizontal LPs, where temporary stations record higher noise levels. We find that median noise levels are extremely homogeneous across the network in the microseismic band (3-20 s) but vary widely outside this range. The amplitudes of microseismic noise display a strong seasonal variation. The seasonality is dominated by very-long-period double-frequency microseisms (8 s), probably associated with winter storms. Stacks of ambient noise amplitudes show that some microseismic noise peaks are visible across the whole ground-motion spectrum, from 0.3 to $100 \mathrm{~s}$. Periods of increased microseismic amplitudes generally correlate with ocean conditions offshore of Portugal. Some seismic records display an interesting $12 \mathrm{hr}$ cycle of LP (100-s) noise, which might be related to atmospheric tides. Finally, we use plots of power spectral density versus time to monitor changes in LP instrumental response. The method allows the identification of the exact times at which LP response changes occur, which is required to improve the understanding of this instrumental artifact and to eventually correct data.
\end{abstract}

Online Material: Figures and movie illustrating the variation of seismic noise amplitudes with sensor type, time, and soil type.

Introduction

Portugal is located on the southwestern tip of the European continent, next to the boundary between the African and Eurasian plates. In this region, oblique convergence between the two plates occurs at a slow rate of $4.5-6 \mathrm{~mm} / \mathrm{yr}$ (Fernandes et al., 2003; Serpelloni et al., 2007). The area marks the transition between convergence to the east, in the Mediterranean, and strike slip to the west, in the Atlantic. Although Portugal has been repeatedly affected by onshore and offshore moderate-to-large earthquakes (Fukao, 1973; Johnston, 1996; Stich et al., 2005; Vilanova and Fonseca, 2007; Fonseca and Vilanova, 2010; Teves-Costa and Batlló, 2011), active seismogenic structures remain poorly under-

*Also at Centro de Geofísica, Universidade de Coimbra, 3040-004 Coimbra, Portugal. stood. The interaction between Nubia and Iberia is thought to create a broad area of deformation, which in turn results in a pattern of diffuse seismicity (Buforn et al., 1995; Borges et al., 2001; Cunha et al., 2012; Bezzeghoud et al., 2014). A proper understanding of how large earthquakes are generated in such slowly deforming environment is lacking.

The dominant geologic feature of western Iberia is the central Iberian massif (CIM), a block of Variscan origin (Dias and Ribeiro, 1995; Simancas et al., 2001, 2003; Onézime et al., 2003; García-Navarro and Fernández, 2004). The Iberian massif is bordered to the west and to the south by the Ceno-Mesozoic Lusitanian and Algarve basins, respectively, both associated with rifting of the Atlantic (e.g., Cloetingh et al., 2002; Casas-Sainz and de Vicente, 2009). In mainland Portugal, the CIM is partially covered by the Douro, Tagus, 
(a)

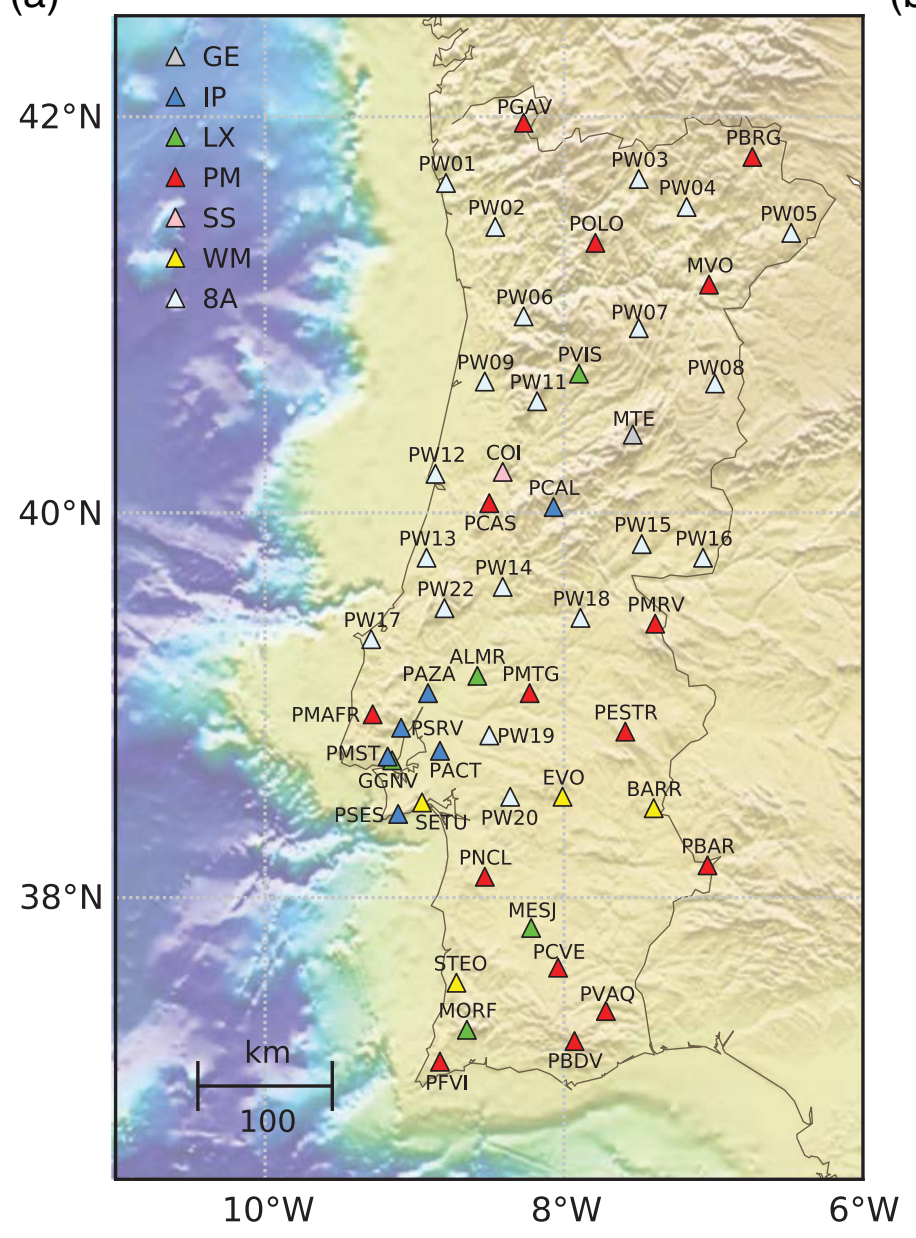

(b)

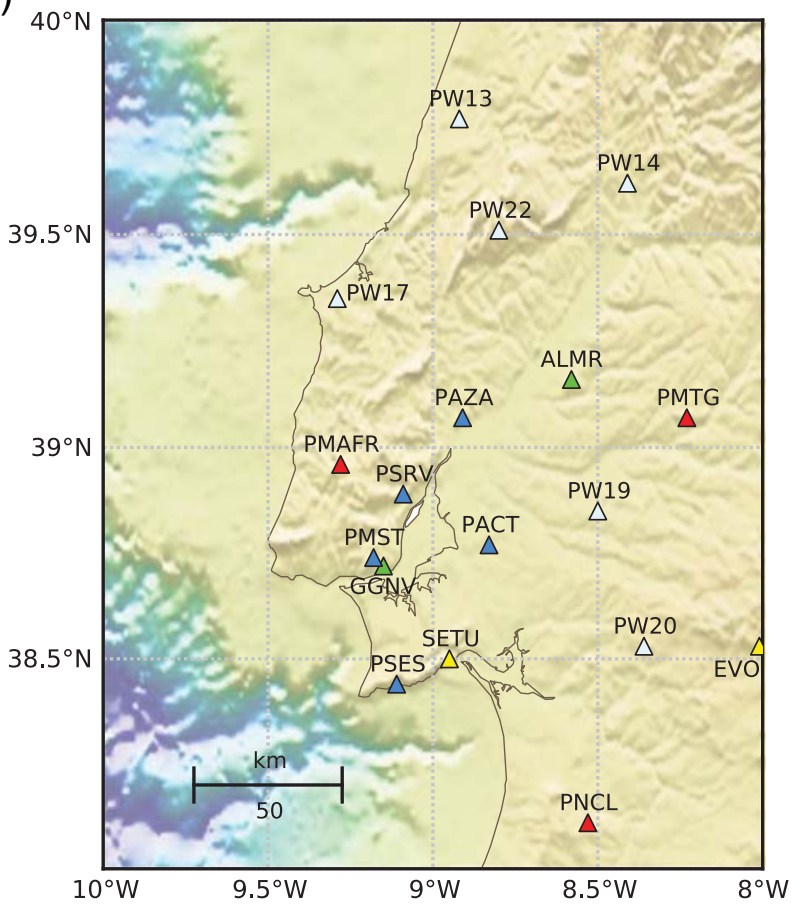

Figure 1. Dense broadband seismic deployment in western Iberia. (a) Locations of WILAS stations, color coded according to network. White triangles mark temporary stations (8A). Permanent stations are operated by Instituto Português do Mar e da Atmosfera (PM, red triangles), GEOFON (GE, gray triangle), Instituto Superior Técnico (IP, dark blue triangles), Instituto Dom Luiz (LX, green triangles), Centro de Geofísica de Coimbra (SS, pink triangle), and Centro de Geofísica de Évora (WM, yellow triangles). (b) Enlarged view of the Lower Tagus Valley (LTV) region. Interstation spacing is $60 \mathrm{~km}$ in general and approximately $30 \mathrm{~km}$ in the LTV. The relief plotted in the background is taken from SRTM30+ (Becker et al., 2009).

and Sado Cenozoic basins, all related to river discharge. Most previous lithospheric studies based on seismic data focused either on the plate boundary region (southern Iberia) or on central Iberia (e.g., Díaz and Gallart, 2009). Current knowledge of the crustal structure under Portugal relies mainly on seismic wide-angle surveys dating back to the 1980s (Victor et al., 1980; Hirn et al., 1982; Díaz et al., 1993). In spite of recent work (Villaseñor et al., 2007; Salah et al., 2011; Monna et al., 2013; Silveira et al., 2013; Palomeras et al., 2014), the lateral extension and interrelation between shallow and deep lithospheric structures have yet to be fully characterized. The impact of tectonic convergence on the structure of the Iberian lithosphere is still unclear, especially to the west, beneath Portugal (e.g., Borges et al., 2001; Cloetingh et al., 2002).

The goal of the WILAS (West Iberia Lithosphere and Asthenosphere Structure) project was to cover Portugal with a temporary dense network of broadband (BB) and very broadband (VBB) seismic stations, providing a high-quality dataset that would contribute to answering some of the outstanding questions above. WILAS encompassed all permanent BB and VBB stations operating in Portugal, run both by the national seismological service (Instituto Português do Mar e da Atmosfera [IPMA]) and by higher education and research institutions (Fig. 1). This dense deployment in Portugal was designed to overlap in time with the IberArray deployment in Spain (Díaz et al., 2010). The two deployments shared similar characteristics and together provide a unique, homogeneous, dense coverage of Iberia. This paper describes the WILAS deployment, characterizes the quality of the seismic data collected, assesses variations in background noise, and characterizes noise sources.

The characterization of ambient noise recorded by seismic networks has been the aim of several studies over the last decades. Peterson (1993) characterized the noise levels of seismic stations distributed worldwide. Based on the power 
spectral density (PSD) of background seismic noise, he defined a new low-noise model (NLNM) and new high-noise model (NHNM), which became standards when comparing noise levels. Stutzmann et al. (2000) and Berger et al. (2004) also used PSD analysis to characterize the noise levels of the global GEOSCOPE network and of the Global Seismographic Network (GSN), respectively. They then discussed sources of seismic noise. McNamara and Buland (2004) proposed a new approach to assess the background seismic noise of networks based on the computation of the probability density functions (PDFs) of PSDs. They applied the method to the continental United States to characterize data collected by the U.S. National Seismograph Network and the Advanced National Seismic System. The proposed methodology is useful to characterize network performance, to detect problems with stations (instrumental and/or related to site conditions), and to prioritize network interventions. The approach proposed by McNamara and Buland (2004) had the advantage of using continuous data and being thoroughly documented and has since been adopted around the world (e.g., Marzorati and Bindi, 2006; Sheen et al., 2009; Evangelidis and Melis, 2012; Grecu et al., 2012; Rastin et al., 2012). The most common main results of the studies listed above include: (1) cultural/ anthropogenic sources significantly affect seismic noise at short-period (SP), which often displays strong diurnal variations; (2) microseismic noise (3-20 s) is strongly affected by seasonal variations and in general is well correlated with oceanic conditions; (3) long-period (LP) seismic noise is often affected by the type of installation and insulation from environmental conditions. In this paper, we follow the methodology proposed by McNamara and Buland (2004).

\section{Seismic Network and Data}

The WILAS experiment comprised all 32 permanent stations running in Portugal plus 20 additional temporary stations. In total, the WILAS network consisted of $52 \mathrm{BB}$ sensors deployed with interstation spacings of approximately $60 \mathrm{~km}$ (Fig. 1a). The Lower Tagus Valley (LTV) was exceptionally densely covered (Fig. 1b). The LTV is a large Cenozoic sedimentary basin, where more than $20 \%$ of the Portuguese population lives, $44 \%$ of the national gross domestic product is generated, and it hosts the capital city of Lisbon. The LTV basin conceals the active fault responsible for the destructive $1909 M_{\mathrm{w}} 6$ Benavente earthquake (Stich et al., 2005; Fonseca and Vilanova, 2010; Teves-Costa and Batlló, 2011). The exact structure of this basin and its seismogenic structures remains under debate (e.g., Besana-Ostman et al., 2012; Cabral et al., 2013; Carvalho et al., 2014).

Most permanent stations are installed in high-quality shelters, such as caves, wells, or concrete surface shelters. They transmit data in real time to the national seismological headquarters at IPMA, using very-small-aperture terminal (VSAT) and Internet connections. Data arrive at IPMA with a latency of $<10 \mathrm{~s}$. In addition, stations operated by univer- sities also transmit data in real time to university labs. Careful quality control is continuously performed at IPMA, including monitoring of background noise levels, gaps, and state of health (batteries, clock drift, etc.). Routine calibration procedures are usually performed once a year.

Temporary stations were equipped with Earth Data PR624 digital recorders and Güralp CMG-3ESP 60 s BB sensors. The locations of temporary stations were chosen primarily so that they would fill gaps between permanent stations, aiming at the predefined interstation distance of $60 \mathrm{~km}$. As secondary criteria, temporary sites should be (1) distant from noise sources, (2) installed on bedrock, and (3) secure. Assessment of soil type was made first using geologic maps and then confirmed in the field during station deployment. Sensors installed on bedrock were directly deployed on granites, schists, etc. Stations in sedimentary basins were deployed in rock outcrops or in compact sediments when rock outcrops could not be found. Only one station (PW19) had to be installed in loose sediments, as no harder rocks could be found nearby. Approximately half of the temporary stations were installed outside buildings, buried below the ground and equipped with solar panels. For safety reasons, the remaining half were deployed inside buildings. Temporary stations stored data on internal disks and thus had to be visited periodically for data retrieval, which resulted in periods of poor data quality at some stations due to instrumental problems or power supply failures that were not timely detected. Both permanent and temporary stations were thermally insulated, first surrounded by a layer of rock wool and then encased in a styrofoam box. The WILAS experiment used a range of sensors, including Güralp and Streckeisen instruments with flat frequency responses up to 30,60 , and $120 \mathrm{~s}$ (Table 1).

The quality control (QC) applied to data included:

1. Defragmentation. Standard for Exchange of Earthquake Data (SEED) daily volumes recorded at a few permanent stations contained data segments that overlapped and/or appeared in nonsequential temporal order. In general, these volumes occupied much more disk space than normal, and the data could not be easily used in subsequent seismic analyses. Data fragmentation sometimes was due to problems in the real-time transmission between the station and data center and sometimes because of communication issues between the sensor and digitizer. We defragmented the data to recover sequential SEED volumes without overlaps.

2. Sensor orientation. At installation, sensors were oriented using a magnetic compass. Field staff reported $\pm 5^{\circ}$ of error in sensor orientation. During quality control, sensor orientation was rechecked according to a procedure based on Grigoli et al. (2012). This analysis allowed the detection of sensor misorientations, which were used to correct the header of dataless files. In some cases, when the computed misorientations could be confirmed by field evidence, the data itself were corrected. Orientation analysis is explained in detail in the next section. 
Table 1

WILAS Seismic Stations

\begin{tabular}{|c|c|c|c|c|c|c|c|}
\hline $\begin{array}{l}\text { Station } \\
\text { Code }\end{array}$ & $\begin{array}{l}\text { Network } \\
\text { Code* }\end{array}$ & $\begin{array}{l}\text { Operation } \\
\text { Period }\end{array}$ & Sensor & $\begin{array}{c}\text { Longitude } \\
\quad\left({ }^{\circ} \mathrm{E}\right)\end{array}$ & $\begin{array}{l}\text { Latitude } \\
\left({ }^{\circ} \mathrm{N}\right)\end{array}$ & $\begin{array}{l}\text { Altitude } \\
(\mathrm{m})\end{array}$ & Site Geology ${ }^{\dagger}$ \\
\hline ALMR & LX & 2010-today & CMG-40T (30 s) & -8.58 & 39.16 & 177 & $\begin{array}{l}\text { Sandstones and conglomerates of Serra de } \\
\text { Almeirim (Pliocene) }\end{array}$ \\
\hline BARR & WM & 2010-today & CMG-3ESP (60 s) & -7.40 & 38.47 & 296 & Intercalated schists (Silurian) \\
\hline COI & SS & 2011-today & STS-2 (120 s) & -8.41 & 40.21 & 140 & $\begin{array}{l}\text { Conglomerates, sandstones, pelites; Castelo } \\
\text { Viegas formation (Triassic) }\end{array}$ \\
\hline EVO & WM & 2007-today & STS2 (120 s) & -8.01 & 38.53 & 235 & $\begin{array}{l}\text { Quartzdiorite and granodiorite (Hercynic } \\
\text { eruptive rock) }\end{array}$ \\
\hline GGNV & LX & 2007-today & CMG-40T (30 s) & -9.15 & 38.72 & 77 & Clays of Prazeres (Miocene) \\
\hline MESJ & $\mathrm{LX}$ & 2007-today & STS2 (120 s) & -8.22 & 37.84 & 250 & $\begin{array}{l}\text { Turbidites, graywacke, conglomerates; } \\
\text { Mértola formation (Carboniferous) }\end{array}$ \\
\hline MORF & LX & 2005-today & CMG-40T (30 s) & -8.65 & 37.30 & 560 & $\begin{array}{l}\text { Nepheline syenite, subvolcanic massif of } \\
\text { Monchique (Cretaceous) }\end{array}$ \\
\hline MTE & GE & 1997-today & STS2 (120 s) & -7.54 & 40.40 & 815 & Granite monzonite (eruptive rock) \\
\hline MVO & PM & 2007-today & CMG-3T (120 s) & -7.03 & 41.16 & 550 & $\begin{array}{l}\text { Slope deposits and aluviums with gravels and } \\
\text { iron (Holocene) }\end{array}$ \\
\hline PACT & IP & 2003-today & CMG-40T (30 s) & -8.83 & 38.77 & 30 & $\begin{array}{l}\text { Clayey sand complex of Coruche (Miocene- } \\
\text { Pliocene) }\end{array}$ \\
\hline PAZA & IP & 2011-today & CMG-40T (30 s) & -8.91 & 39.07 & 52 & $\begin{array}{l}\text { Detritic complex of Ota Carmanal and layers } \\
\text { of V. N. da Rainha (Miocene) }\end{array}$ \\
\hline PBAR & PM & 2007-today & $\begin{array}{l}\text { CMG-3ESP/3T } \\
\qquad(120 \mathrm{~s})\end{array}$ & -7.04 & 38.17 & 205 & Turbidites; Terena formation (Devonian) \\
\hline PBDV & PM & 2007-today & CMG-3ESP (120 s) & -7.93 & 37.24 & 471 & Turbidites; Mira formation (Carboniferous) \\
\hline PBRG & PM & 2008-today & CMG-3ESP (120 s) & -6.74 & 41.80 & 690 & $\begin{array}{l}\text { Granulites; Morais complex (Proterozoic- } \\
\text { Cambrian) }\end{array}$ \\
\hline PCAL & IP & 2010-today & STS-2 (120 s) & -8.07 & 40.03 & 474 & Turbidites; Perais formation (Cambrian) \\
\hline PCAS & PM & 2009-today & CMG-3T (120 s) & -8.50 & 40.05 & 343 & $\begin{array}{l}\text { Limestones, chert-bearing limestones } \\
\text { Degracias formation (Jurassic) }\end{array}$ \\
\hline PCVE & PM & 2007-today & CMG-3ESP (120 s) & -8.04 & 37.63 & 225 & $\begin{array}{l}\text { Turbidites; Mértola formation } \\
\text { (Carboniferous) }\end{array}$ \\
\hline PESTR & PM & 2006-today & CMG-3T (120 s) & -7.59 & 38.87 & 410 & $\begin{array}{l}\text { Dolomites, crystalline dolomitic limestones } \\
\text { (Cambrian) }\end{array}$ \\
\hline PFVI & PM & 2007-today & CMG-3ESP (120 s) & -8.83 & 37.13 & 189 & Schists and graywackes (Carboniferous) \\
\hline PGAV & PM & 2008-today & CMG-3ESP (120 s) & -8.27 & 41.97 & 1084 & Serra Amarela granites (Hercynian rock) \\
\hline PMAFR & PM & 2006-today & STS2 (120 s) & -9.28 & 38.96 & 329 & Praia de Banhos sandstones (Cretaceous) \\
\hline PMRV & PM & 2007-today & CMG-3ESP (120 s) & -7.39 & 39.43 & 430 & Calcareous-alkaline granites (magmatic rock) \\
\hline PMST & IP & 2003-today & CMG-40T (30 s) & -9.18 & 38.74 & 175 & Volcanic complex of Lisboa (Cretaceous) \\
\hline PMTG & PM & 2008-today & CMG-3ESP (120 s) & -8.23 & 39.07 & 190 & $\begin{array}{l}\text { Amphibolites; Monte de Portugal formation } \\
\text { (Cambrian-Ordovician) }\end{array}$ \\
\hline PNCL & PM & 2008-today & CMG-3ESP (120 s) & -8.53 & 38.11 & 120 & $\begin{array}{l}\text { Turbidites; Mértola formation } \\
\text { (Carboniferous) }\end{array}$ \\
\hline POLO & PM & 2008-today & CMG-3ESP (120 s) & -7.79 & 41.37 & 1060 & Granites; Vila Real massif (Hercynian rock) \\
\hline PSES & IP & 2011-today & STS-2 (120 s) & -9.11 & 38.44 & 87 & Azóia limestones (Jurassic) \\
\hline PSRV & IP & 2010-today & CMG-3ESP (60 s) & -9.09 & 38.89 & 351 & Basaltic dyke \\
\hline PVAQ & PM & 2006-today & CMG-3T (120 s) & -7.72 & 37.40 & 200 & $\begin{array}{l}\text { Turbidites; Mértola formation } \\
\text { (Carboniferous) }\end{array}$ \\
\hline PVIS & LX & 2011-today & STS2 (120 s) & -7.90 & 40.71 & 626 & $\begin{array}{l}\text { Turbidites and conglomerates; Rosmaninhal } \\
\text { formation (Cambrian) }\end{array}$ \\
\hline PW01 & $8 \mathrm{~A}$ & 2010-2012 & CMG-3ESP (60 s) & -8.79 & 41.67 & 110 & Alkaline granites (eruptive rocks) \\
\hline PW02 & $8 \mathrm{~A}$ & 2010-2012 & CMG-3ESP (60 s) & -8.46 & 41.45 & 160 & $\begin{array}{l}\text { Granites of Guimarães and St. Tirso } \\
\text { (Hercynian rock) }\end{array}$ \\
\hline PW03 & $8 \mathrm{~A}$ & 2010-2012 & CMG-3ESP (60 s) & -7.50 & 41.69 & 526 & Schists and granites complex (Silurian) \\
\hline PW04 & $8 \mathrm{~A}$ & 2010-2012 & CMG-3ESP (60 s) & -7.18 & 41.55 & 247 & Schists; volcanic siliceous complex (Silurian) \\
\hline PW05 & $8 \mathrm{~A}$ & 2010-2012 & CMG-3ESP (60 s) & -6.48 & 41.42 & 651 & Cabonaceous schists (Ordovician) \\
\hline PW06 & $8 \mathrm{~A}$ & 2011-2012 & CMG-3ESP (60 s) & -8.27 & 41.00 & 350 & $\begin{array}{l}\text { Schists and graywackes } \\
\text { Schist-graywacke complex (pre-Ordovician) }\end{array}$ \\
\hline PW07 & $8 \mathrm{~A}$ & 2010-2012 & CMG-3ESP (60 s) & -7.50 & 40.94 & 900 & $\begin{array}{l}\text { Schists; Schist-graywacke complex } \\
\quad \text { (Cambrian) }\end{array}$ \\
\hline PW08 & $8 \mathrm{~A}$ & 2010-2012 & CMG-3ESP (60 s) & -6.99 & 40.66 & 748 & Granites, granites monzonite (Cambrian) \\
\hline PW09 & $8 \mathrm{~A}$ & 2010-2012 & CMG-3ESP (60 s) & -8.53 & 40.67 & 78 & $\begin{array}{l}\text { Clayey schists, Arada schists of Schist- } \\
\text { graywacke complex (pre-Ordovician) }\end{array}$ \\
\hline
\end{tabular}


Table 1 (Continued)

\begin{tabular}{|c|c|c|c|c|c|c|c|}
\hline $\begin{array}{l}\text { Station } \\
\text { Code }\end{array}$ & $\begin{array}{l}\text { Network } \\
\text { Code* }\end{array}$ & $\begin{array}{l}\text { Operation } \\
\text { Period }\end{array}$ & Sensor & $\begin{array}{l}\text { Longitude } \\
\left({ }^{\circ} \mathrm{E}\right)\end{array}$ & $\begin{array}{l}\text { Latitude } \\
\left({ }^{\circ} \mathrm{N}\right)\end{array}$ & $\begin{array}{l}\text { Altitude } \\
(\mathrm{m})\end{array}$ & Site Geology ${ }^{\dagger}$ \\
\hline PW11 & $8 \mathrm{~A}$ & 2010-2012 & CMG-3ESP (60 s) & -8.18 & 40.57 & 792 & Granites (orogenic rock sin-tectonic) \\
\hline PW12 & $8 \mathrm{~A}$ & 2010-2011 & CMG-3ESP (60 s) & -8.86 & 40.20 & 444 & Limestones and marls (Jurassic) \\
\hline PW13 & $8 \mathrm{~A}$ & 2010-2012 & CMG-3ESP (60 s) & -8.92 & 39.77 & 80 & $\begin{array}{l}\text { Clayey sands and gravels complex, with } \\
\text { sandstones (Pliocene-Pleistocene) }\end{array}$ \\
\hline PW14 & $8 \mathrm{~A}$ & 2010-2012 & CMG-3ESP (60 s) & -8.41 & 39.62 & 105 & Limestones and marls of Tomar (Jurassic) \\
\hline PW15 & $8 \mathrm{~A}$ & 2010-2012 & CMG-3ESP $(60 \mathrm{~s})$ & -7.48 & 39.84 & 390 & Granite monzonite (eruptive rock) \\
\hline PW16 & $8 \mathrm{~A}$ & 2010-2012 & CMG-3ESP (60 s) & -7.07 & 39.77 & 302 & $\begin{array}{l}\text { Arkosic conglomerates of Cabeço do Infante } \\
\text { (Paleogene) }\end{array}$ \\
\hline PW17 & $8 \mathrm{~A}$ & 2010-2011 & CMG-3ESP (60 s) & -9.29 & 39.35 & 95 & Sandstones (Jurassic) \\
\hline PW18 & $8 \mathrm{~A}$ & 2010-2012 & CMG-3ESP (60 s) & -7.89 & 39.46 & 227 & $\begin{array}{l}\text { Phyllites and graywackes } \\
\text { Schist-graywacke complex (Precambrian) }\end{array}$ \\
\hline PW19 & $8 \mathrm{~A}$ & 2010-2012 & CMG-3ESP (60 s) & -8.50 & 38.85 & 108 & $\begin{array}{l}\text { Clayey sand complex of Coruche (Miocene- } \\
\text { Pliocene) }\end{array}$ \\
\hline PW20 & $8 \mathrm{~A}$ & 2010-2012 & CMG-3ESP (60 s) & -8.36 & 38.53 & 272 & $\begin{array}{l}\text { Schists and sandstones; Horta da Torre } \\
\text { formation (Devonian) }\end{array}$ \\
\hline PW22 & $8 \mathrm{~A}$ & 2012-2012 & CMG-3ESP (60 s) & -8.80 & 39.51 & 510 & Limestones of Chão das Pias (Jurassic) \\
\hline SETU & WM & 2008-today & CMG-3ESP (60 s) & -8.95 & 38.50 & 117 & $\begin{array}{l}\text { Clays, sandstones, conglomerates, and } \\
\text { limestones of Vale de Rasca (Jurassic) }\end{array}$ \\
\hline STEO & WM & 2010-today & CMG-3ESP (60 s) & -8.72 & 37.55 & 119 & $\begin{array}{l}\text { Sands, sandstones, and gravels of Baixo } \\
\text { Alentejo and V. Sado (Pliocene- } \\
\text { Pleistocene) }\end{array}$ \\
\hline
\end{tabular}

*See Figure 1 for station locations.

${ }^{\dagger}$ Site geology was assessed using geological maps (Carta Geológica de Portugal:-1:50000, 1:200,000, and 1:500,000).

3. Background noise. Background noise recorded at each site was monitored via PSD analysis, in real time for the stations relayed to IPMA and a posteriori for all the dataset.

\section{Sensor Orientation}

Knowledge of true sensor orientation is critical for many seismological studies, such as for waveform modeling, computation of receiver functions, or SKS polarization analysis. In spite of the care taken in the installation of very sensitive BB and VBB sensors, both in permanent and temporary networks, comparisons between field gyroscope measurements and a posteriori analysis of polarized seismic signals show that carefully oriented seismometers can be misoriented by more than $10^{\circ}$ (e.g., Ekström and Busby, 2008, and references therein). In this section, we examine the orientation of seismometers of the WILAS network, applying a modified version of the ROTAZIONE method (Grigoli et al., 2012) to the $P$ waves of large earthquakes.

WILAS partners adopted different field procedures to orient sensors. IPMA's standard procedure is to orient sensors to geographic north, using a magnetic compass and compensating for local magnetic declination. Observations of the magnetic field in Portugal are made only at a few selected points, and the declination at the remaining locations is obtained by modeling. Instituto Dom Luiz (IDL) oriented the sensors to the magnetic north, considering that the average value of magnetic declination in mainland Portugal $\left(3^{\circ} \mathrm{W}\right)$ is smaller than the reported error of field deployment $\left(5^{\circ}\right)$. The remaining partners oriented sensors to geographic north, using a magnetic compass and compensating for a constant declination of $3^{\circ} \mathrm{W}$. These different approaches, together with an incomplete knowledge of the magnetic field in Portugal, are likely to have introduced fluctuations in sensor orientations. Because temporary stations were deployed by teams of all partner institutions, issues with sensor orientation are pervasive in the WILAS network.

In order to assess sensor orientation a posteriori, we used seismic waves. The method developed by Grigoli et al. (2012) relies on the assumption that all sensors record the same incident plane wave. This ideal condition is never met, but the method can be confidently applied when the correlation between waveforms recorded at pairs of instruments is high, a condition verified when the dominant wavelength is larger than interstation spacing. The original method poses no restriction on the polarization of waves, at odds with other methods that use highly polarized waves such as the first $P$ wave or LP Rayleigh waves (e.g., Ekström and Busby, 2008, and references therein).

We investigated five shallow earthquakes with $M_{\mathrm{w}}>6.5$, located at distances between $60^{\circ}$ and $90^{\circ}$ from the WILAS array center (Fig. 2). Thus, we obtained $P$ waves incident on the WILAS array close to the vertical, which were likely to originate similar waveforms at neighbor stations (Table 2). We also analyzed waveforms of the Lorca, Spain, earthquake (event 6). This earthquake cannot be considered a teleseismic event but provides high amplitude $P$-wave recordings.

After preliminary quality control based on the visual inspection of diagnostic plots and on the assessment of cross correlations between waveforms, we obtained more than 30 valid $P$ waveforms for each event. The selected waveforms were band-pass filtered between 0.05 and $0.5 \mathrm{~Hz}$ and 


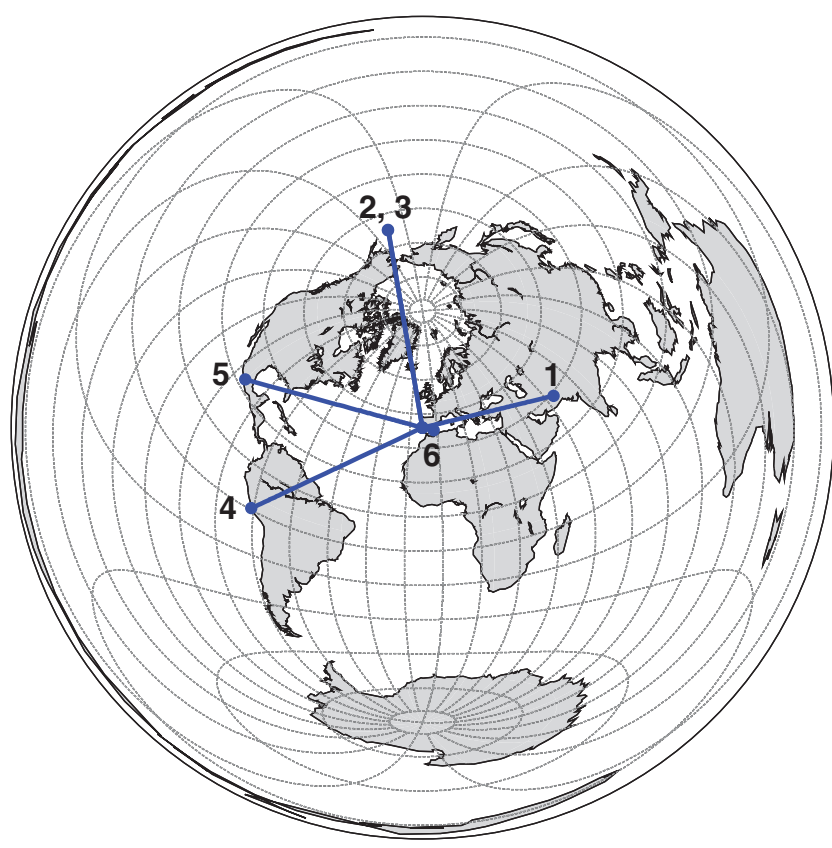

Figure 2. Locations of the six earthquakes used to investigate the orientation of WILAS sensors. Two of the events (2 and 3) occurred at close locations and cannot be distinguished in the figure. The numbers of the events refer to the locations provided in Table 2.

decimated. To account for small differences in the azimuths between stations and events, which become relevant for close events, we rotated the recordings to the presumed radial and transverse axes.

The second step of ROTAZIONE consists of aligning all traces with respect to a common reference time and normalizing the amplitude of every trace with respect to the maximum horizontal displacement of one of the traces. Next, a time window for the analysis is defined, which can be done interactively on the screen or using a common window for all traces. We chose to analyze the first pulse of the $P$ waves, which was very coherent in the vertical waveforms.

Finally, the relative orientation of seismic sensors is inferred. We will not present here the details of this procedure, instead we refer the reader to the original article for a complete description. ROTAZIONE computes relative sensor orientations for consecutive pairs of instruments. If $\hat{S}^{i}$ is the complex of the seismic trace recorded at sensor $i$, a dataset with $k$ sensors can be represented by the vector

$$
\left[\hat{S}^{1}, \hat{S}^{2}, \hat{S}^{3}, \ldots, \hat{S}^{k}\right]
$$

The original ROTAZIONE method uses an inversion scheme to derive the $k-1$ angles between pairs of sensors, $\theta^{j}$ :

$$
\theta^{j}: \hat{S}^{j-1}=\hat{S}^{j} e^{i \theta^{j}}, \quad j=2,3, \ldots, k .
$$

If the first trace represents a reference station, then the rotation angles relative to the reference can be obtained by summing the successive pairs of relative rotations:

$$
\theta_{\text {ref }}^{1}=0, \quad \theta_{\text {ref }}^{j}=\sum_{i=1}^{j} \theta^{i}, \quad j=2,3, \ldots, k .
$$

Using this approach, statistical errors will accumulate, attaining unreasonable values when many pairs of stations are used. In addition, while the rotations are determined for consecutive pairs of stations, the optimal time alignment (step 2 above) is performed using only the first trace as reference. In order to overcome these two issues, we modified the original ROTAZIONE method to compute the orientation of sensors relative to the first trace, as done for time alignment, instead of computing relative orientations for consecutive pairs of stations. Thus, we directly obtain the values on the left side of equation (3). Because the true orientation of sensor 1 is unknown, these values can be interpreted as the differences between the true orientations of sensor pairs:

$$
\theta_{1}^{j}=\theta_{\text {true }}^{1}-\theta_{\text {true }}^{j}, \quad j=2,3, \ldots, k
$$

We then generalize this procedure so that all possible pairs of sensors are considered:

$\theta_{\text {ref }}^{j}=\theta_{\text {true }}^{\text {ref }}-\theta_{\text {true }}^{j}, \quad j=2,3, \ldots, k, \quad$ ref $=1,2, \ldots, k-1$.

Equation (5) is a set of $k(k-1) / 2$ equations for $k$ unknown parameters $\theta_{\text {true }}^{j}$. We solve this overdetermined system using single value decomposition (Press et al., 2007). The covariance matrix, a posteriori errors, and a $\chi^{2}$ diagnostic (absolute and normalized) are also computed.

A priori errors on measurements are estimated from the normalized cross correlation between waveforms recorded at pairs of stations. We selected for inversion equations

Table 2

Earthquakes Used for Station Orientation

\begin{tabular}{cccccccc}
\hline Event & Date $(\mathrm{yyyy} / \mathrm{mm} / \mathrm{dd})$ & Time $(\mathrm{hh}: \mathrm{mm}: \mathrm{ss})$ & $M_{\mathrm{w}}$ & Longitude $\left({ }^{\circ} \mathrm{E}\right)$ & Latitude $\left({ }^{\circ} \mathrm{N}\right)$ & Epicentral Distance $(\mathrm{km})$ & Back-Azimuth $\left({ }^{\circ}\right)$ \\
\hline 1 & $2011 / 01 / 18$ & $20: 23: 23$ & 7.2 & 63.95 & 28.78 & 6578 & 76 \\
2 & $2011 / 06 / 24$ & $03: 09: 39$ & 7.3 & -171.84 & 52.05 & 9805 & 350 \\
3 & $2011 / 09 / 02$ & $10: 55: 53$ & 6.9 & -171.71 & 52.17 & 9790 & 350 \\
4 & $2011 / 10 / 28$ & $18: 54: 34$ & 6.9 & -75.97 & -14.44 & 9183 & 245 \\
5 & $2011 / 12 / 11$ & $01: 47: 25$ & 6.5 & -99.96 & 17.84 & 8942 & 285 \\
6 & $2011 / 05 / 11$ & $18: 47: 26$ & 5.1 & -1.673 & 37.699 & $474-752$ & $82-135$ \\
\hline
\end{tabular}


corresponding to station pairs for which the waveforms had a normalized cross correlation above a threshold of 0.85 . We also rejected all equations that corresponded to a time shift between waveforms larger than a predefined maximum of $2.0 \mathrm{~s}$ (in practice, the time shift was either below $0.9 \mathrm{~s}$ or much higher than $2.0 \mathrm{~s}$ ). Using this method, we obtained the set of rotation angles that corresponds to the best waveform correlations for all station pairs. These angles are still relative, but they can be converted to true sensor orientation if the orientation of one station is independently known.

Let us recall that the original method of Grigoli et al. (2012) imposed no restrictions on waveform polarization. Our second modification relies on the assumption that the $P$ wave is polarized on the radial-vertical $(R-Z)$ plane between station and event, which allows the inference of absolute sensor orientation. For each station, we created a synthetic reference pair using the vertical waveform along the radial axis with a null transverse component. We then used ROTAZIONE to compute the best rotation angle that transformed the observed horizontal components into the synthetic trace. The eigenvalues of the covariance matrix between the three ground-motion components were used to define the degree of rectilinearity and planarity of the waveforms. Only absolute rotation angles inferred from large rectilinearity and small planarity waveforms were further processed. Appropriate thresholds were defined considering that the first $P$-wave pulse is expected to be near rectilinear. In our application, we required the rectilinearity parameter, defined from the covariance matrix eigenvalues, to be at minimum 0.6.

Using the modified version of ROTAZIONE, we obtained for each event a set of relative rotation angles between pairs of stations and a set of absolute rotation angles for each station. This information is finally used together in an overdetermined system of equations that we solve by single value decomposition (Press et al., 2007). In total, we obtained 268 equations for 55 unknowns. We report results obtained for stations with a minimum of three measurements (i.e., two earthquake measurements plus the synthetic measurement). The final $\chi^{2}$ of the inverse procedure was 32.5 .

Table 3 shows the true orientation of sensors with respect to geographic north for the 34 best-constrained station orientations. The associated error is estimated from single value decomposition and is scaled so that the normalized $\chi^{2}$ is one. The number of equations used to define the orientation of each sensor is also shown. Two stations, PCAB and PVIS, show a large dispersion of the inferred values for sensor orientation and should be further investigated.

This investigation allowed us to detect two extreme cases, EVO (permanent station) and PW18 (temporary station), in which the sensors had been incorrectly oriented by $90^{\circ}$ and $180^{\circ}$, respectively. Once these misorientations were confirmed in the field, data were corrected and the orientation analysis recomputed. Our analysis indicates that more than half the stations (19/34) deviated from north by less than $5^{\circ}$ (Fig. 3). Only six stations show deviations larger than $10^{\circ}$ :
Table 3

Sensor Orientation Results for the Best-Constrained Solutions

\begin{tabular}{|c|c|c|c|}
\hline Station & $\begin{array}{l}\text { Azimuth from } \\
\text { North }\left({ }^{\circ}\right)\end{array}$ & $\begin{array}{l}\text { Error of Inferred } \\
\text { Orientation }\left(^{\circ}\right)\end{array}$ & $\begin{array}{l}\text { Number of } \\
\text { Equations }\end{array}$ \\
\hline ECAL & -2.6 & 4.3 & 8 \\
\hline EVO & $\langle-10.0\rangle$ & $\langle 6.6\rangle$ & 5 \\
\hline MESJ & $\langle\langle-11.0\rangle\rangle$ & $\langle 6.7\rangle$ & 6 \\
\hline MORF & $\langle-7.2\rangle$ & $\langle 6.6\rangle$ & 5 \\
\hline MTE & -4.2 & 4.0 & 8 \\
\hline MVO & $\langle-5.5\rangle$ & 4.0 & 10 \\
\hline PAZA & $\langle\langle 10.9\rangle\rangle$ & $\langle 6.2\rangle$ & 4 \\
\hline PBAR & $\langle-7.0\rangle$ & $\langle 5.8\rangle$ & 4 \\
\hline PBDV & 3.9 & $\langle 5.7\rangle$ & 6 \\
\hline PBRG & 1.9 & $\langle 5.3\rangle$ & 5 \\
\hline PCAB & 2.6 & $\langle\langle 11.6\rangle\rangle$ & 3 \\
\hline PCAS & -3.3 & 3.6 & 9 \\
\hline PCBR & -2.2 & $\langle 8.8\rangle$ & 3 \\
\hline PCVE & $\langle\langle 16.8\rangle\rangle$ & 5.0 & 7 \\
\hline PESTR & 0.9 & 4.6 & 11 \\
\hline PFVI & $\langle\langle 14.1\rangle\rangle$ & $\langle 6.5\rangle$ & 7 \\
\hline PGAV & -4.7 & 2.0 & 6 \\
\hline PMAFR & $\langle-9.5\rangle$ & 4.8 & 8 \\
\hline PMRV & 0.5 & 4.2 & 11 \\
\hline PMST & -4.3 & $\langle 6.6\rangle$ & 8 \\
\hline PMTG & $\langle\langle-16.3\rangle\rangle$ & 4.8 & 6 \\
\hline PNCL & -2.1 & 4.6 & 9 \\
\hline POLO & 1.1 & 4.0 & 10 \\
\hline PVAQ & $\langle\langle 35.0\rangle\rangle$ & $\langle 5.6\rangle$ & 7 \\
\hline PVIS & 4.0 & $\langle\langle 10.9\rangle\rangle$ & 3 \\
\hline PW03 & -3.6 & 4.0 & 7 \\
\hline PW04 & -5.0 & $\langle 8.4\rangle$ & 4 \\
\hline PW05 & $\langle-6.6\rangle$ & $\langle 6.7\rangle$ & 7 \\
\hline PW06 & -1.7 & 4.0 & 8 \\
\hline PW08 & -0.3 & 3.7 & 10 \\
\hline PW09 & $\langle 5.9\rangle$ & 3.9 & 8 \\
\hline PW15 & -2.8 & 4.9 & 6 \\
\hline PW16 & $\langle-7.6\rangle$ & 3.6 & 10 \\
\hline PW19 & $\langle-8.9\rangle$ & $\langle 8.3\rangle$ & 3 \\
\hline
\end{tabular}

Values between \langle\rangle indicate sensors misoriented by values between, or with errors in computed orientation between, $5^{\circ}$ and $10^{\circ}$. Values between $\langle\langle\rangle$ indicate sensors misoriented by more than, or with errors in computed orientation larger than, $10^{\circ}$.

PAZA, MESJ, PFVI, PMTG, PCVE, and PVAQ. PVAQ is the station with the largest deviation from north, a feature that had already been noted by regional waveform modelers. This station is installed in an underground tunnel, which creates added difficulties for proper orientation. The azimuths of approximately half the stations (18/34) were estimated with errors smaller than $5^{\circ}$.

\section{Background Noise Analysis}

We used probabilistic power spectral densities (PPSDs) to characterize the seismic ambient noise recorded at each station-component. PPSDs were obtained using the methodology proposed by McNamara and Buland (2004) and implemented in the software package ObsPy (Beyreuther et al., 2010). In this paper, we follow the ObsPy terminology and use the expression "probabilistic power spectral density" (PPSD) to refer to the "probability density function" (PDF) 


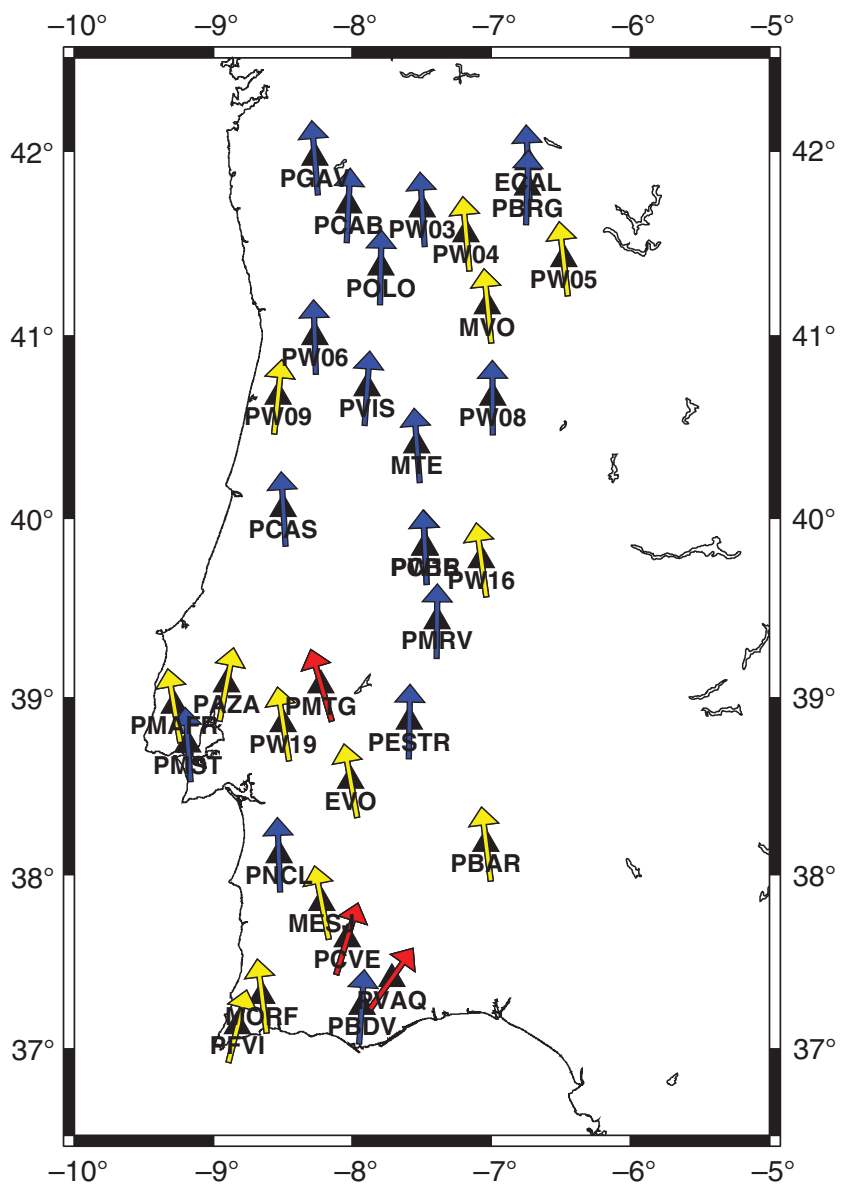

Figure 3. True orientation of sensors (shown only for sensors with a reliable orientation assessment). Colored arrows indicate sensors with misorientations lower than $5^{\circ}$ (blue), between $5^{\circ}$ and $10^{\circ}$ (yellow), and more than $10^{\circ}$ (red). Black triangles mark station locations.

of McNamara and Buland (2004). Here, we will only review briefly how PPSDs are computed, referring the more interested reader to the original references. Continuous streams of seismic data are analyzed in windows of $1 \mathrm{hr}$ that move in steps of $30 \mathrm{~min}$. Preprocessing of the $1 \mathrm{hr}$ segments includes segmentation into 13 windows that overlap by $75 \%$, truncation to the next lower power of 2 , and subtraction of the mean and tapering. Next, a fast Fourier transform (FFT) is applied to all data segments, and PSDs are obtained from the FFT components. At this point, the instrument response is removed by spectral division, and the corrected PSD is converted to decibels with respect to acceleration $\left(1 \mathrm{~m} / \mathrm{s}^{2}\right)$. The PSDs are now in the units of $\left(\mathrm{m} / \mathrm{s}^{2}\right)^{2} / \mathrm{Hz}$. PSDs for each $1 \mathrm{hr}$ data segment are obtained by averaging the PSDs of the 13 segments. In order to reduce computational load, PSDs are resampled so that we keep only one data point per 1/8 of octave, guaranteeing an adequate spacing in logarithmic frequency space. We thus obtained smoothed PSD estimates for every $1 \mathrm{hr}$ data segment.

Next, we assess how often an amplitude is observed for each period of acceleration. To this end, we compute histo-
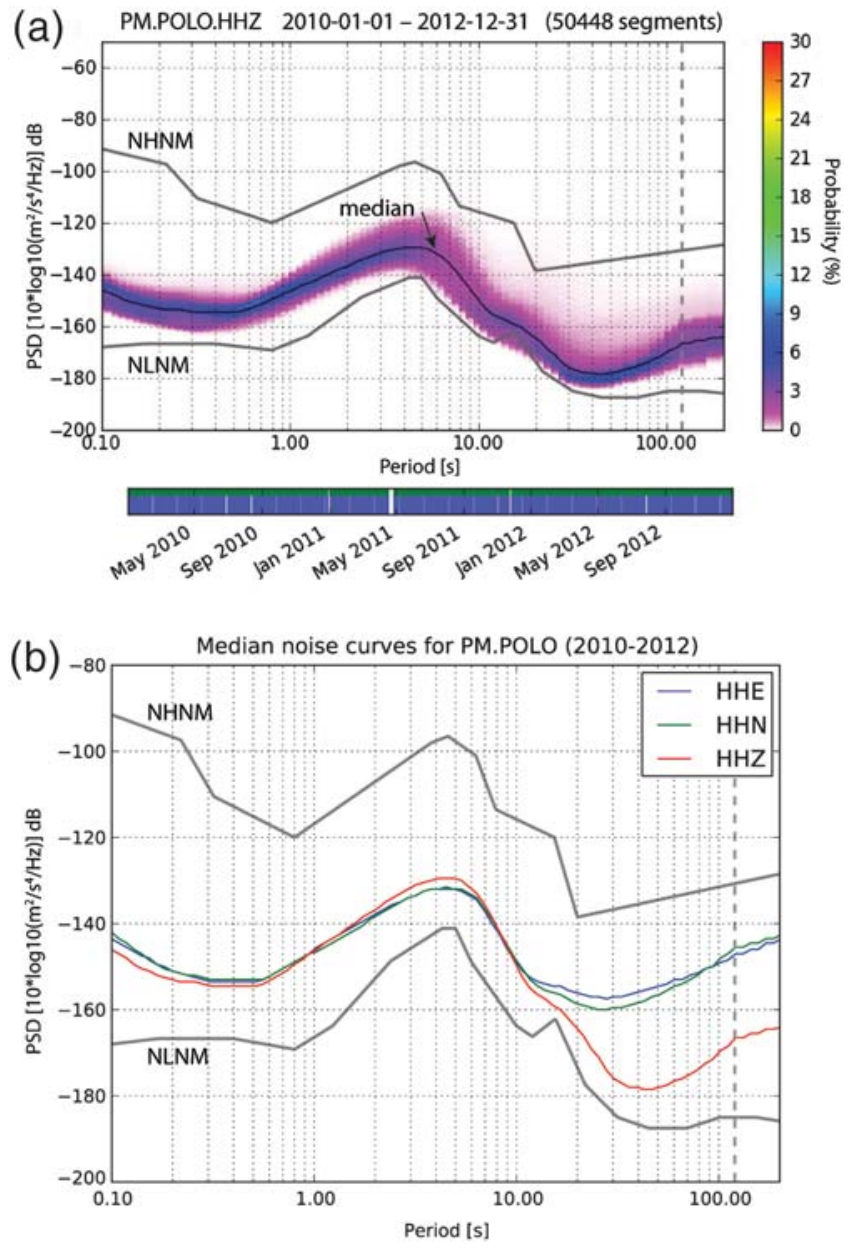

Figure 4. Characterization of background seismic noise. (a) Probabilistic power spectral density (PPSD) of ground acceleration recorded at station POLO (vertical direction, $Z$ ). Amplitudes in red are the most frequently observed, amplitudes in pink are observed with the lowest probability, and amplitudes in white are not observed. The median noise level is shown by a black line. The bar below the PPSD shows data used: green patches represent data available and fed into the PPSD, and blue patches show single PSD measurements that go into the histogram. In this example, we used data for the $3 \mathrm{yr}$ period 2010-2012, corresponding to 50,448 $1 \mathrm{hr}$ segments. (b) Median noise levels for east-west (blue), north-south (green), and vertical (red) components of ground acceleration. Both plots show the new low-noise model (NLNM) and new high-noise model (NHNM) of Peterson (1993) for reference. The dashed vertical line marks the instrumental cut-off frequency (120 s).

grams (frequency distributions) of the amplitudes recorded at each period based on all smoothed PSDs. A PDF is estimated from the histogram for each center period. The final plots of PPSDs show the amplitudes more often observed at each period in red (Fig. 4a). At the opposite end of the scale, pink shows the amplitudes less frequently observed, or in other words, observed with lower probability. Figure 4 a shows that the background noise amplitude at station POLO (vertical direction) lies between the NLNM and the NHNM of Peterson (1993). The black line shows the median noise level, which corresponds to the 50th percentile of the PPSD. In most cases, 

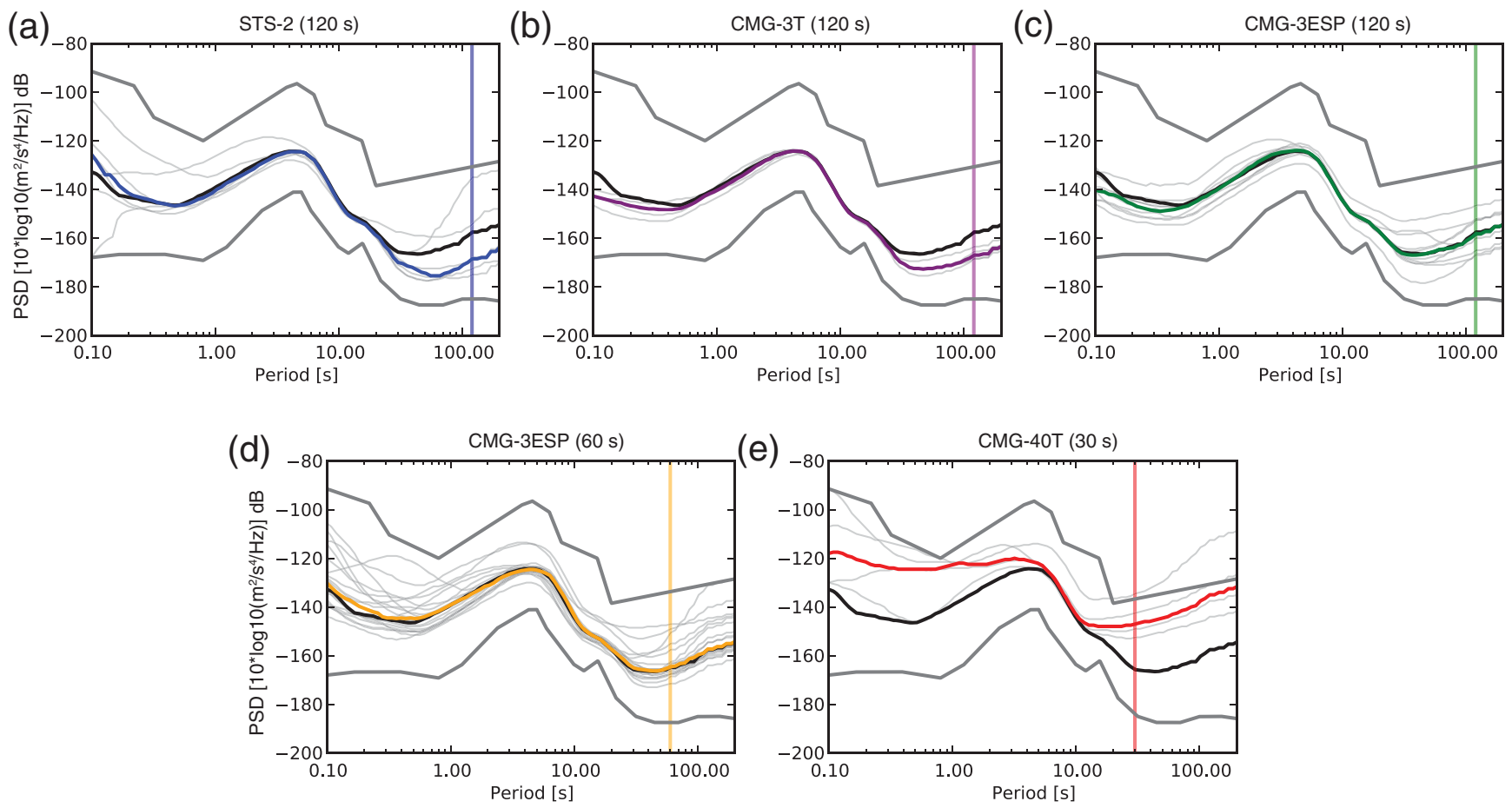

Figure 5. Median noise curves divided according to instrument type: (a) STS2 $120 \mathrm{~s}$, (b) CMG-3T 120 s, (c) CMG-3ESP 120 s, (d) CMG-3ESP $60 \mathrm{~s}$, and (e) CMG-40T $30 \mathrm{~s}$ (red). The thin gray lines show noise levels at individual stations. Colored thick lines show the median noise levels of all stations equipped with a given sensor. The thick black line is the median noise curve of all stations in the network. Only vertical recordings are considered in this plot. The colored vertical lines show the cut-off frequency of each sensor. Instrument type does not significantly affect seismic noise amplitudes up to $10 \mathrm{~s}$. Only CMG-40T (30 s) records higher noise amplitudes at short periods (SPs). Long-period (LP) noise amplitudes depend strongly on instrument type. (E) Similar figures are provided for one horizontal component (east-west [EW]) in Figure S1. The curves for the north-south (NS) components are very similar to the EW.

median and mean noise levels are very similar. Because the median is less sensitive to outliers than the mean, and is less sensitive to system transients than the mode, in this paper we use the median to represent ensembles of noise curves. For the sake of simplicity, we use the expression "noise level" to refer to the median noise curve for each station-component, unless otherwise specified. Figure $4 b$ shows the noise levels for all three components of ground motion at station POLO: east-west (EW), north-south (NS), and vertical (Z).

\section{Characterization of Background Noise}

A concern that arises in a deployment that encompasses different types of sensors run by different operators is whether the data collected are homogeneous. Figure 5 shows that noise levels recorded at the WILAS array are independent of sensor type up to $10 \mathrm{~s}$. Above $10 \mathrm{~s}$, different sensors record very different noise levels. At LPs, the quietest sensors are the Streckeisen STS-2 (120 s), followed closely by the Güralp CMG-3T (120 s). Curiously, the Güralp CMG3ESP with cut-off frequencies of 120 and $60 \mathrm{~s}$ present identical noise levels at all periods. As expected, the noisiest instrument in the LP range is the CMG-40T (30 s). This sensor also shows high noise levels at SPs $(<1 \mathrm{~s})$ at three of four sites, which may arise from cultural noise sources.
Figure 6 shows the difference between noise recorded at temporary and permanent sites. The difference remains small all along the spectra for the vertical component and becomes large for LPs recorded at horizontal components (more than $15 \mathrm{~dB}$ ). The increased amplitudes of LP horizontal noise at temporary sites is a well-known phenomenon related to the poorer insulation from atmospheric variations (Wilson et al., 2002; Díaz et al., 2010). (E) This phenomenon can also be seen in Figure S1, available in the electronic supplement to this article, which shows noise amplitudes for different instruments in the east-west direction. In contrast to vertical recordings, where Güralp CMG-3ESP 120- and 60-s sensors displayed similar noise levels, the temporary stations (CMG-3ESP 60-s) display a higher noise level at LPs on horizontal recordings.

Figure 7 shows the typical plots that we used for QC: PPSDs, spectrograms, and plots of PSD versus time. Both spectrograms and plots of PSD versus time are computed directly from the PSDs obtained according to the method of McNamara and Buland (2004). PSD is plotted versus time at the chosen frequencies of $0.3,4,7,17,33$, and 100 s. PSD versus time plots were originally introduced by García et al. (2006) to monitor the Teide volcano, Canary Islands, and later implemented at the Data Center of the Observatories and Research Facilities for European Seismology for routine QC (Sleeman and Vila, 2007). 
(a)

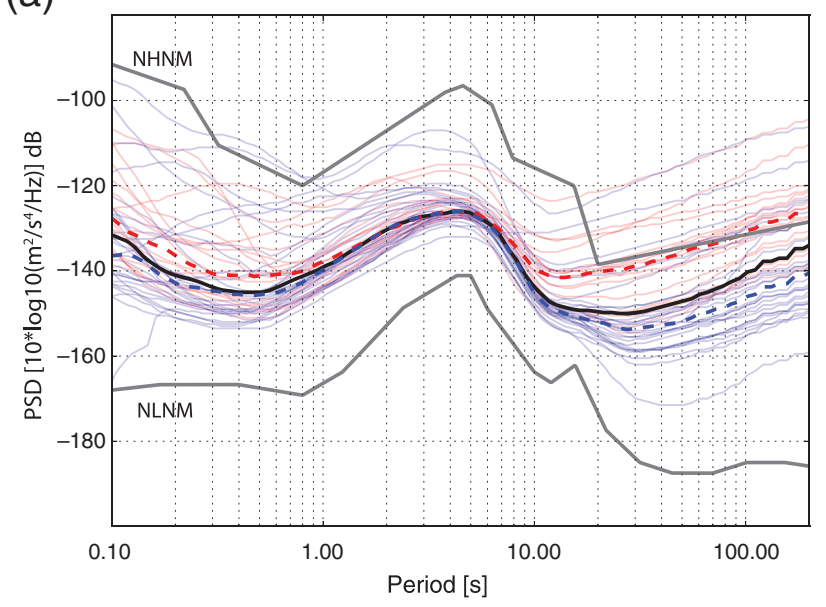

(b)

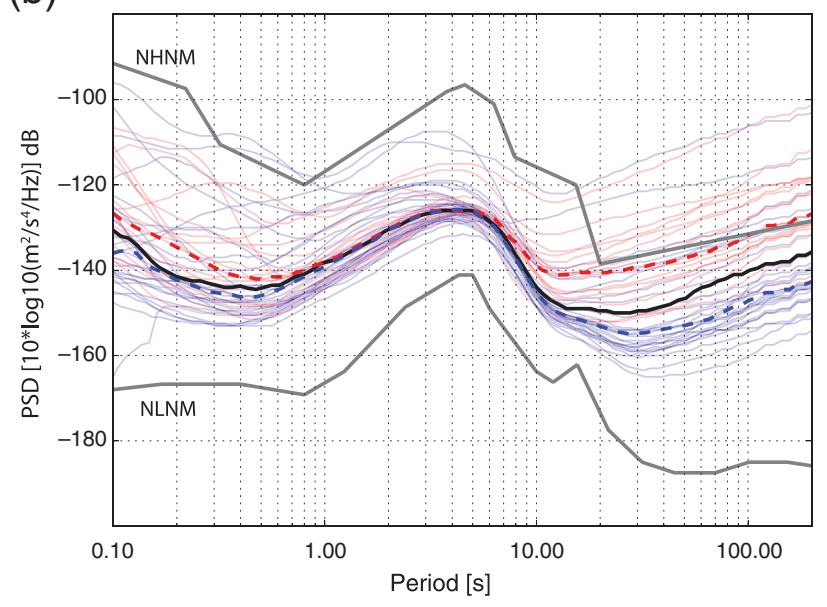

Z

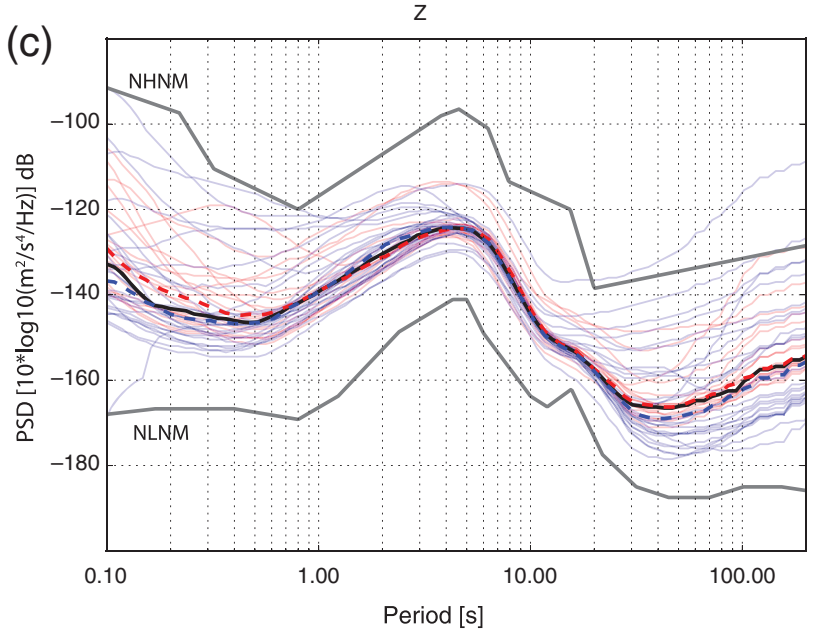

Figure 6. Median noise curves for all stations (thin lines) color coded according to type of installation: permanent (blue) and temporary (red). The thick dashed lines show the median of the noise levels recorded at permanent (blue) and temporary (red) sites. The thick black line is the median of the noise levels recorded at all stations. (a) EW, (b) NS, and (c) vertical (Z). The noise levels of temporary and permanent stations are very similar across the whole spectrum except for LP horizontal components, where temporary stations register much higher noise levels than permanent stations.
Next, we analyze the ambient noise recorded at the WILAS array on the SP range (periods smaller than $1 \mathrm{~s}$ ), on the microseismic range (periods between 3 and $20 \mathrm{~s}$ ), and on the LP range (periods longer than $20 \mathrm{~s}$ ). Station-components PW04-N, PW13-ENZ, PW17-ENZ, PSES-ENZ, and SETU-ENZ were removed from the analysis due to instrumental problems (power failures, time synchronization issues, Global Positioning System failures, blocked seismometer components, and failures to reboot or damage).

\section{Short-Period Noise}

Figure $8 \mathrm{a}-\mathrm{c}$ shows the median noise levels at all stations for the three directions of ground motion. The colored solid and dashed lines show the median and average of all noise levels per component, respectively. The average noise curve has a slightly higher amplitude than the median curve, although the two are similar. SP noise amplitudes vary significantly across the network in all components of ground motion. SP vertical noise is of slightly lower amplitude than horizontal (Fig. 8d). At SPs, we expect seismic recordings to be affected by small, local sources of noise, such as anthropogenic sources and wind turbulence (e.g., Stutzmann et al., 2000; McNamara and Buland, 2004). The fact that noise amplitudes vary widely between stations confirms a local origin of SP seismic energy.

Short-period daily variations of noise occur both at temporary and permanent stations but are in general stronger at temporary sites. (E) Figure S2 shows the difference between day (1 p.m. to 5 p.m.) and night (1 a.m. and 5 a.m.) noise levels at periods of $0.3 \mathrm{~s}$. The difference between day and night noise levels goes up to $18 \mathrm{~dB}$ in one extreme case (PW18), is on the order of 8-10 dB at most stations strongly affected by this variability, and is less than $2 \mathrm{~dB}$ at the stations less affected. SP daily cycles are often related to human activity and are a common observation worldwide (e.g., Peterson, 1993; McNamara and Buland, 2004; Díaz et al., 2010). Figure 7 characterizes the seismic noise recorded in the east-west direction at the temporary station PW04. The daily cycle of SP noise is clear both on the spectrogram and on the plot of PSD at $0.3 \mathrm{~s}$ versus time (purple curve), with noise decreasing during the night and increasing during the day. Daily SP cycles are sometimes directly visible on the PPSDs as a bimodal distribution (Fig. 7a). (E) SP noise decreases during the weekend at some stations, confirming its cultural origin (Fig. S3).

\section{Microseismic Noise}

The interaction between oceans and solid Earth causes an increase in seismic background noise in the so-called microseismic band, which is recorded in stations around the world. Primary microseisms, or single-frequency (SF) microseisms, are recorded at 10-20 s. They have the same period as ocean swell and are thought to be generated by direct pressure of ocean waves on the seafloor or by the breaking of waves at the coast (Hasselmann, 1963). Through coupling 
(a)

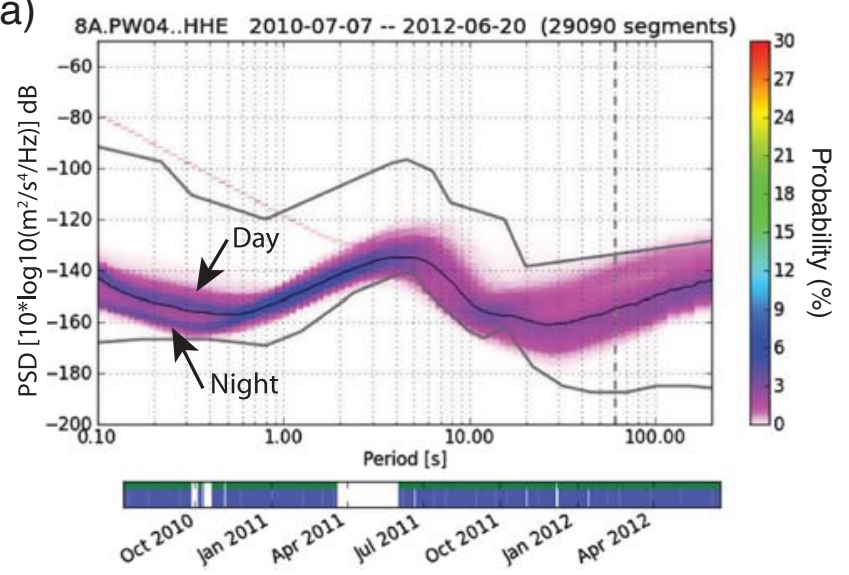

(b)

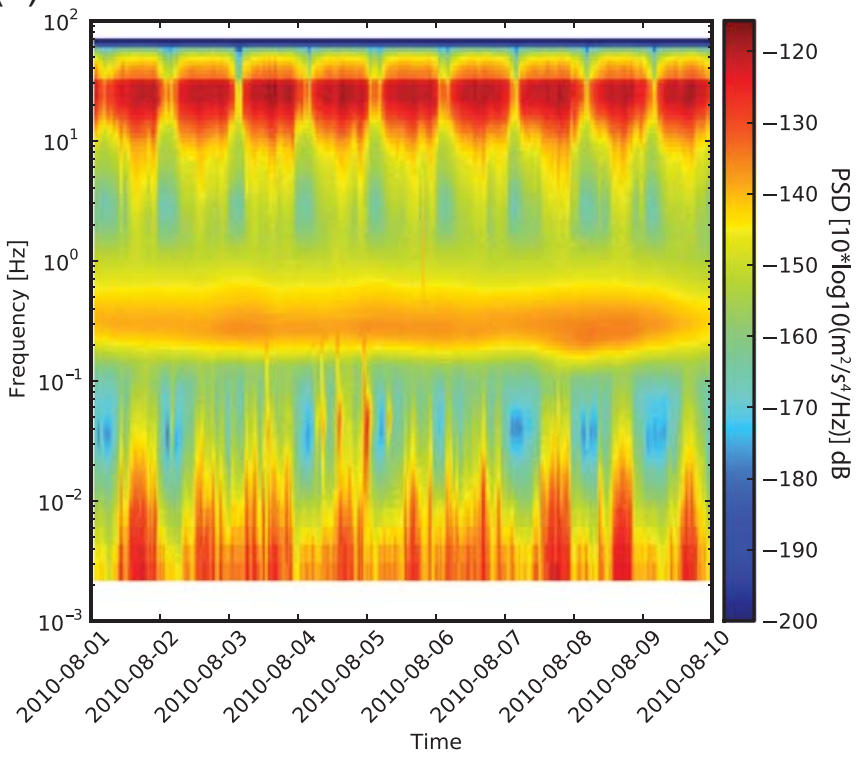

(c)

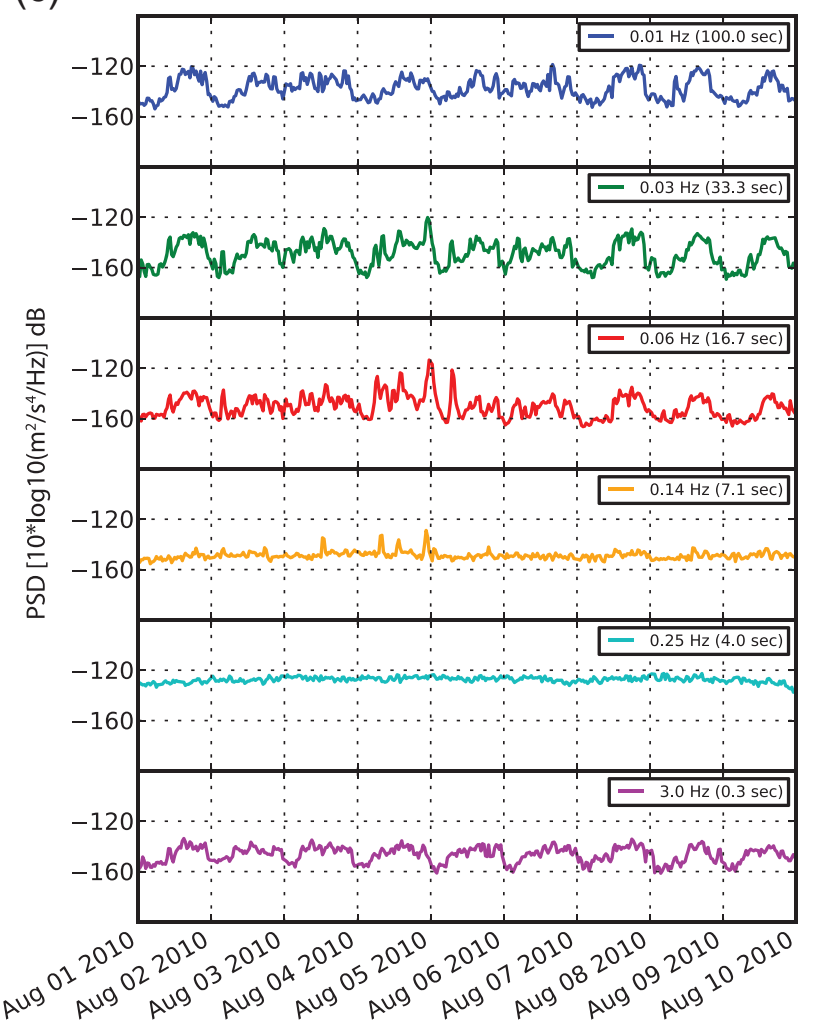

Figure 7. (a) Probabilistic power spectral densities (PPSDs) of seismic noise recorded at temporary station PW04-E, installed near an urban area. The two lines of higher probability at SPs show the day and night noise levels. (b) Spectrogram of ambient noise based on the computed PSDs. Daily variations are again evident. (c) Temporal evolution of power spectral density (PSD) at ground acceleration periods of $0.3 \mathrm{~s}$ (pink), $4 \mathrm{~s}$ (light blue), $7 \mathrm{~s}$ (yellow), $17 \mathrm{~s}$ (red), $33 \mathrm{~s}$ (green), and $100 \mathrm{~s}$ (dark blue) during a 10-day period. A clear daily cycle is visible both on SP and LP noises.

between swell and bathymetry, incident ocean waves transfer their energy to the solid Earth. The efficiency of this mechanism decays quickly with increasing water depth. Therefore, SF microseisms are thought to be generated in shallow waters only. Using linear wave theory, Bromirski (2001) estimated that 15 and $20 \mathrm{~s}$ ocean waves are expected to start interacting with the seafloor at water depths less than 350 and $624 \mathrm{~m}$, respectively.

Double-frequency (DF) microseisms are recorded most prominently between 3 and $10 \mathrm{~s}$. They are recorded with a frequency that is twice that of ocean swell and have an amplitude that is much larger than SF microseisms. Longuet-Higgins (1950) first explained the generation of DF microseisms, and Tanimoto (2007a) and Webb (2007) later expanded the theory. When two opposing ocean waves with similar wavelengths collide, they generate a standing wave with twice the frequency of the original waves. This standing wave causes a pressure perturbation at the seafloor for which the amplitude depends only on the product of the amplitudes of the original waves and not on seafloor depth. Thus, a pressure fluctuation acts on the seafloor, although the energy from the original waves did not reach the seafloor directly. An accumulating body of evidence suggests that DF microseisms are most frequently generated in coastal regions (Haubrich and McCamy, 1969; Bromirski and Duennebier, 2002; Schulte-Pelkum et al., 2004; Bromirski et al., 2005; Rhie and Romanowicz, 2006; Tanimoto, 2007b). DF microseisms are thought to be frequently generated in coastal areas by the interaction of swell with coastal reflections. However, strong DF microseisms may also be generated during strong storms in deep oceans or when a swell meets another independent swell or a wind sea, provided they share 

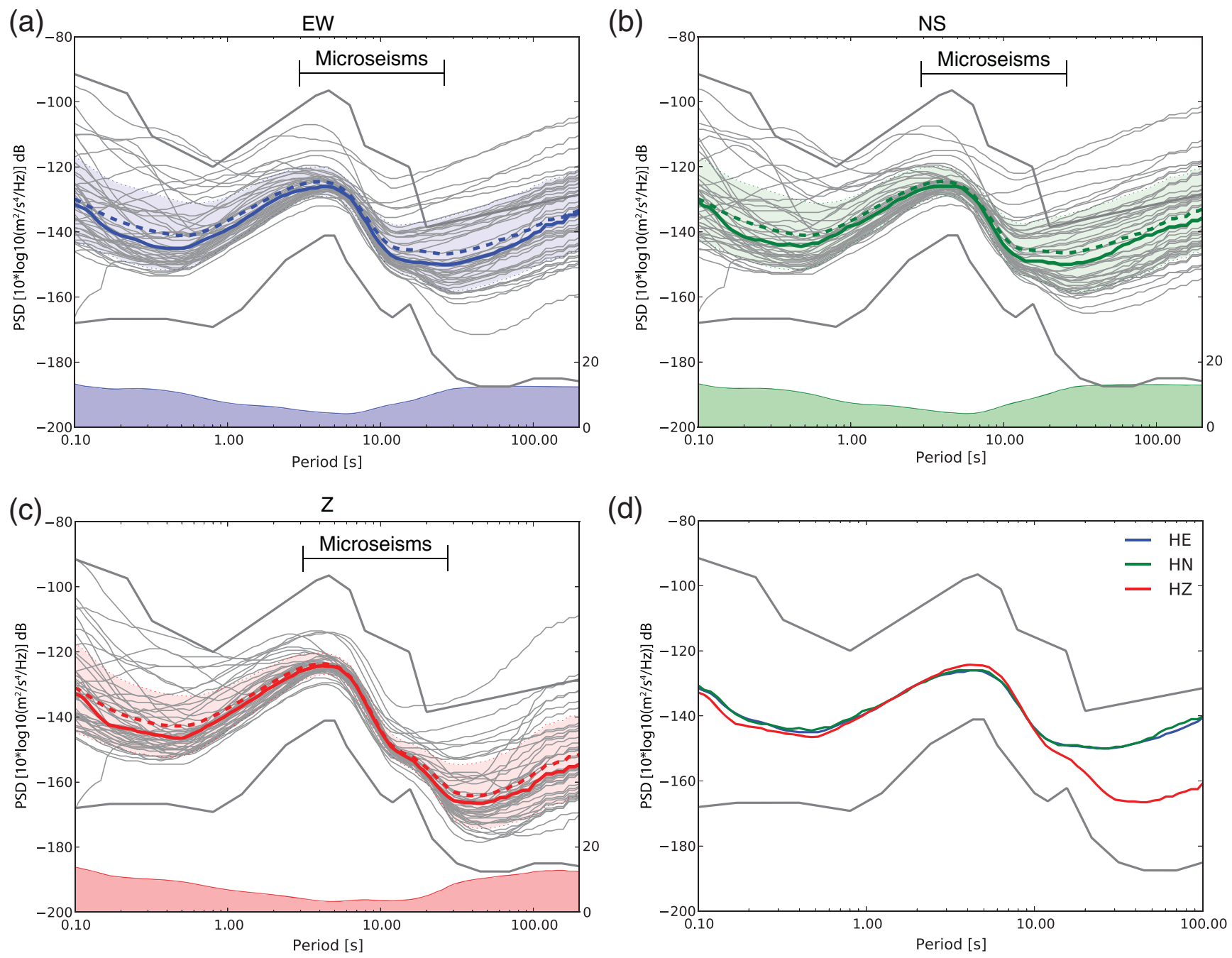

(d)

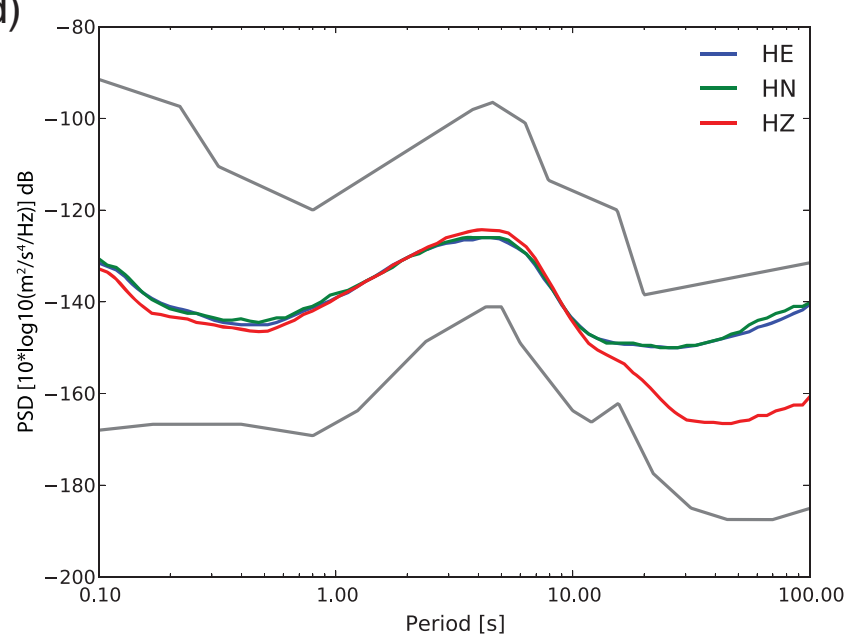

Figure 8. Median noise curves (gray lines) recorded at all stations of the WILAS experiment in the (a) east-west, (b) north-south, and (c) vertical $(Z)$ directions. The colored solid and dashed lines, respectively, show the median and the average of all station noise levels (gray lines) per component of ground motion. Note that the median and average curves are very similar. The standard deviation of noise levels is shown in shaded colors around the average curve and also at the bottom of the figure in absolute value (scale on the right). Very similar noise amplitudes are recorded at all stations in the microseismic band. The standard deviation of noise levels is low at the DF peak on all components of ground motion. In addition, the standard deviation is low at the SF peak only in the vertical direction. Noise amplitudes diverge outside the microseismic band. (d) Median of noise levels recorded at all stations in the EW (blue), NS (green), and Z (red) directions.

similar wavelengths (Ardhuin et al., 2012, and references therein). Because the sources of microseisms are acoustic, they preferentially generate Rayleigh waves, which propagate efficiently at periods longer than a few seconds (Haubrich and McCamy, 1969; Bromirski and Duennebier, 2002).

Identical noise levels are recorded at different stations in Portugal in the microseismic range, between 3 and 20 s (DF and SF peaks) on the $Z$ component and between 3 and $8 \mathrm{~s}$ (DF peak only) on horizontal components (Fig. 8a-c). Webb (1998) observed the same collapsing of background noise amplitudes in the microseismic range when comparing a station in California with another in Hawaii. Most Portuguese stations are positioned within $200 \mathrm{~km}$ of the Atlantic ocean. Oceanic processes are likely to act as common sources of seismic energy, which is then recorded across the network with identical amplitudes. At the DF peak, around $5 \mathrm{~s}$, vertical noise presents higher amplitudes than horizontal noise at most stations (Figs. 4b and 8d). In contrast, vertical noise amplitudes are normally lower than horizontal noise amplitudes outside the microseismic band. A similar observation was previously made for the GSN minimum noise levels (Berger et al., 2004). Figure 9 compares the geographical distribution of the difference between vertical and horizontal noise amplitudes at the DF peak (4-6 s) with two proxies for very shallow crustal structure. We use both geologic information and topographic slope as proxies for the average shear-wave velocity of the shallowest $30 \mathrm{~m}\left(V_{S 30}\right)$. The geologic $V_{S 30}$ map is based on information about surface geology, taking into account lithology and age of rocks (Teves-Costa et al., 2010). The $V_{S 30}$ map based on 

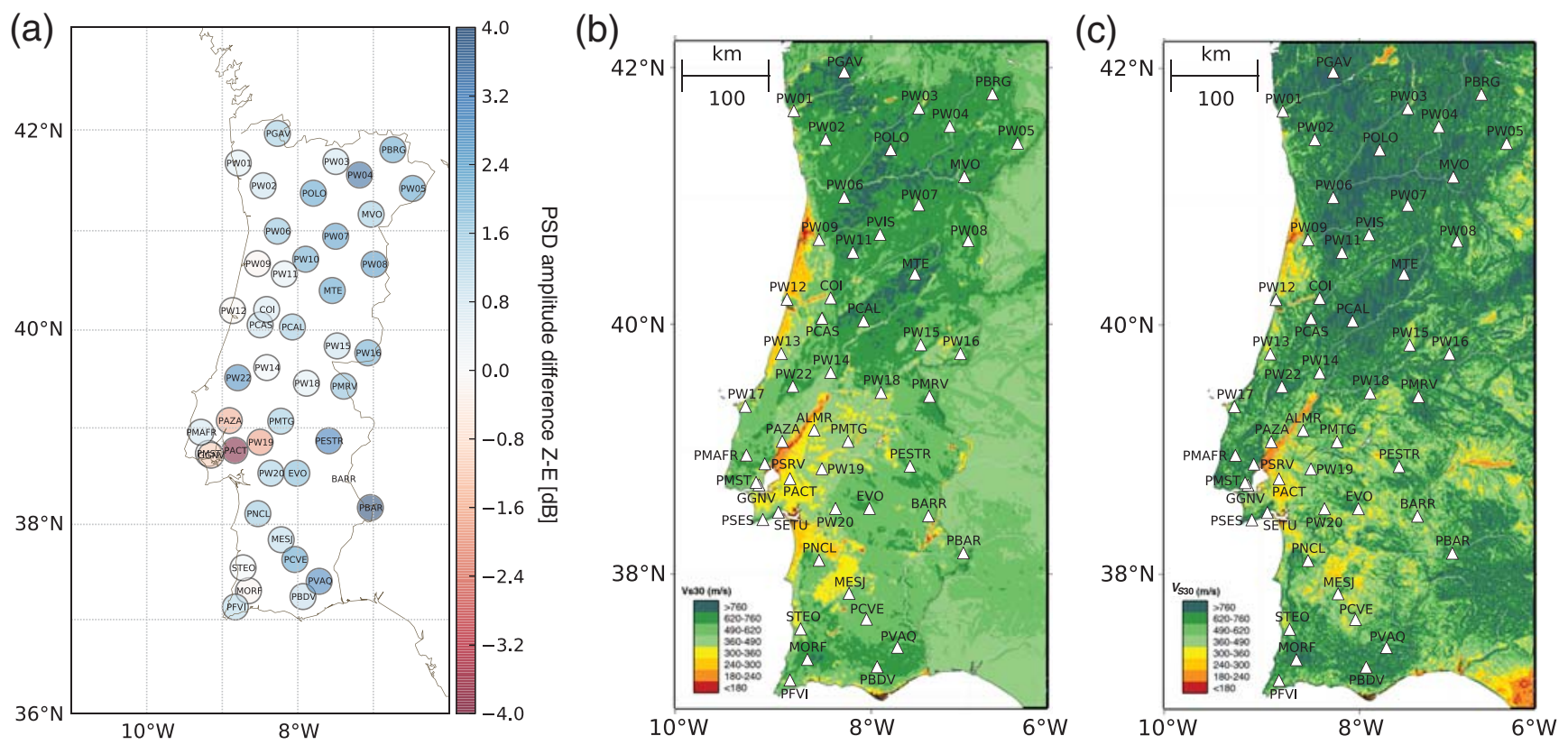

Figure 9. (a) Difference between vertical $(Z)$ and horizontal (E) noise amplitudes at the DF peak (4-6 s). (b) The map of $V_{S 30}$ is based on geologic information (Teves-Costa et al., 2010). (c) The map of $V_{S 30}$ based on topographic slope, following Wald and Allen (2007). Sites with higher horizontal noise amplitudes at the DF peak lay on the sedimentary basin of the Tagus valley (PAZA, PMST, GGNV, PACT, and PW19) and also on the Lusitanian basin (PW09 and PW12), whereas stations with higher vertical noise amplitudes sit on hard rock. The difference between horizontal and vertical noise amplitudes in this frequency range is likely related to the ellipticity of Rayleigh waves.

topographic slope was computed according to the methodology proposed by Wald and Allen (2007). Narciso et al. (2012) are currently developing a more reliable map of $V_{S 30}$ based on a regional database of shear-wave velocity data, combined with geologic, geographic, and lithologic informations. Their preliminary results indicate that while some geologic units can be consistently characterized by a common value of $V_{S 30}$, others show a significant spread of $V_{S 30}$ values. They also showed that the estimation of $V_{S 30}$ based on topographic slope results in accurate values for some geologic classes but not for others. The proxies for $V_{S 30}$ presented here should thus be interpreted only as indicative. The analysis of the strongest common features of Figure 9 indicates that horizontal amplitudes are larger than vertical amplitudes in stations located on sediments (PAZA, PMST, GGNV, PACT, and PW19 in the LTV basin; PW09 and PW12 in the Lusitanian basin), while the opposite occurs for stations located on hard-rock sites. This observation is likely related to the ellipticity of Rayleigh waves, which dominate the noise spectrum at the DF peak. In sediments, the elliptical particle motion of Rayleigh waves becomes flattened (mostly horizontal), whereas at hard-rock sites it becomes vertically elongated (e.g., Tanimoto et al., 2013).

Microseismic noise shows a clear seasonal modulation, with higher amplitudes observed during winter (Fig. 10). We observe the typical dislocation of the DF peak toward longer periods, from $3.5 \mathrm{~s}$ in the summer months of June, July, and August to $6 \mathrm{~s}$ during the winter months of December, January, and February. The difference between winter and summer DF peaks is approximately $4.5 \mathrm{~dB}$ in all three components of ground motion. This dislocation of the DF peak is generally attributed to the longer period swell generated during winter storms (e.g., Stutzmann et al., 2000). The SF peak is only clearly visible during winter months, although a hint of it appears during summer months on vertical records. The difference between summer and winter noise amplitudes is most noticeable at $8 \mathrm{~s}$, where it attains a maximum of $15 \mathrm{~dB}$. A second peak in seasonality is observed at $17 \mathrm{~s}(8 \mathrm{~dB}$ on vertical records), coincident with the SF peak. Seasonality of the $17 \mathrm{~s}$ peak is most clear on vertical records, whereas seasonality of the $8 \mathrm{~s}$ noise is equally visible across all components of ground motion. The peak of DF seasonality ( $8 \mathrm{~s})$ is of longer period than the DF peaks in our dataset, during both summer ( $3.5 \mathrm{~s}$ ) and winter (6s). This observation confirms the notion that the seasonality of DF microseisms is dominated by very-LP swell events associated with large ocean storms.

(E) Figure S4 shows the time evolution of vertical noise amplitudes recorded across the network, during the $3 \mathrm{yrs}$ of our analysis, for different periods of ground acceleration. Thin lines are obtained by smoothing the temporal evolution of PSDs for a given period at a given station. Thick lines at the top are stacks of the smoothed noise amplitudes recorded at all stations (thin lines). The variation of ambient noise amplitudes is extremely coherent across the network at all microseismic periods $(4,7$, and $17 \mathrm{~s}$ in this study). Figure $\mathrm{S} 4$ highlights again the strong seasonality of $7 \mathrm{~s}$ noise.

Let us now turn our attention to the relation between ambient seismic noise and oceanic and atmospheric 
(a)

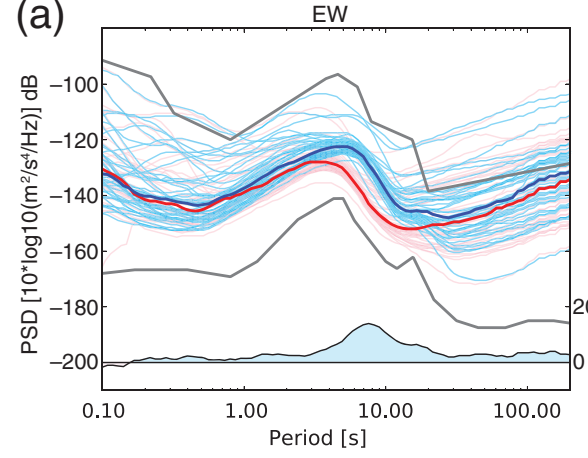

(b)

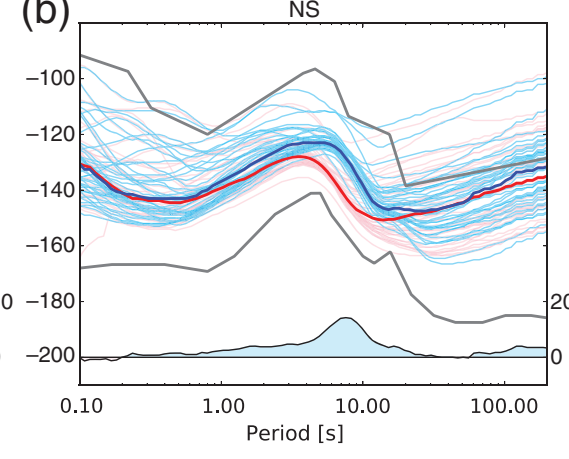

(c)

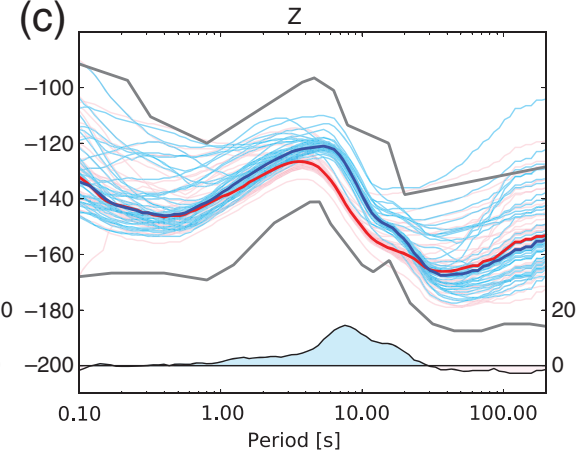

Figure 10. Median noise amplitudes recorded at all stations during the winter months of December, January, and February (light blue lines) and during the summer months of June, July, and August (pink lines). The blue and red thick lines show the medians of the noise levels recorded during winter and summer, respectively. The difference between noise recorded during winter and summer, calculated as the difference between winter and summer median curves (red and blue thick lines), is shown by the black curve at the bottom of the plot (scale on the right). The area under this curve is shaded in blue or red depending on whether the noise is higher during winter or summer, respectively. The difference between noise recorded during summer and winter is largest at 7-8 s, with a second peak at 17 s. (a) EW, (b) NS, and (c) Z directions.
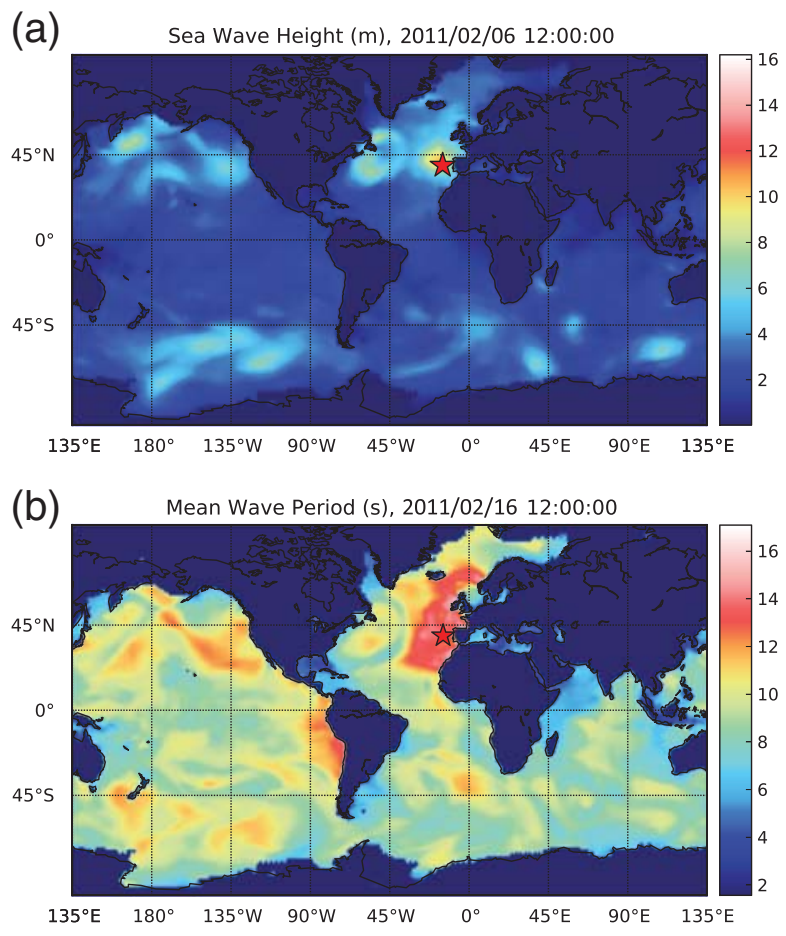

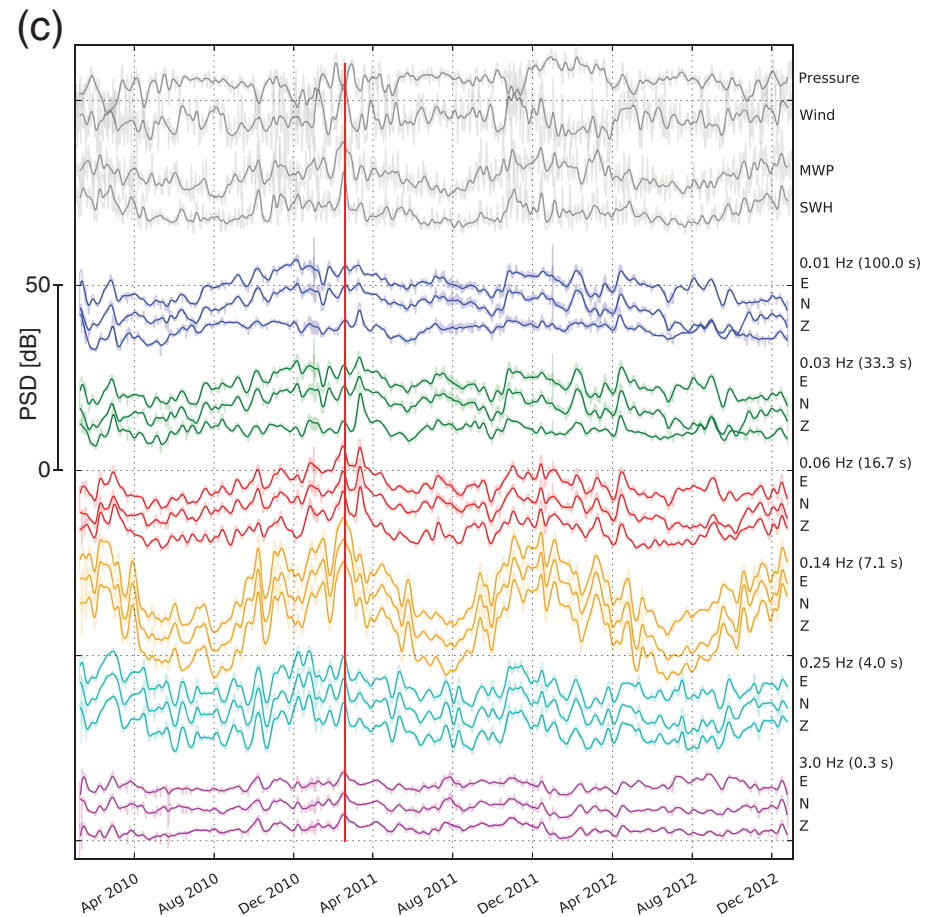

Figure 11. Plot of oceanic and atmospheric variables and of noise amplitudes recorded at different ground-motion periods and components, on 16 February 2011, 12:00 UTC. (a) Worldwide distribution of sea wave height (SWH) and (b) mean wave period (MWP) according to the reanalysis of European Center for Medium Range Weather Forecasting (ECMWF). The red star marks a reference location on the edge of the continental platform offshore of Portugal, at $10^{\circ} \mathrm{W}$ and $40^{\circ} \mathrm{N}$. (c) The atmospheric and oceanic variables for the chosen reference location (gray lines, top) and stacked seismic noise amplitudes (colored lines, bottom). Atmospheric pressure, wind intensity, MWP, and SWH (gray lines, top) were all obtained from ECMWF reanalysis. Seismic noise amplitudes at the ground-motion periods of $100 \mathrm{~s}$ (blue), $33 \mathrm{~s}$ (green), $17 \mathrm{~s}$ (red), $7 \mathrm{~s}$ (yellow), $4 \mathrm{~s}$ (cyan), and $0.3 \mathrm{~s}$ (pink) are smoothed stacks of ambient noise recorded across the network. The vertical red line marks the chosen date and time (16 February 2011, 12:00 UTC). (a, b) An event with high SWH and MWP hitting the coast of Portugal. Simultaneously, peaks of seismic noise are observed at all periods, from 0.3 to $100 \mathrm{~s}$.

variables. Figure 11a shows the significant height of combined wind waves and swell (for simplicity, in this article we will refer to this parameter as sea wave height [SWH]), and Figure 11b shows the mean wave period (MWP), both extracted from reanalysis of the European Center for Medium Range Weather Forecasting (ECMWF). These panels image an ocean storm during the winter of 2011. Figure $11 \mathrm{c}$ shows atmospheric pressure, wind intensity, 
SWH, and MWP, also extracted from ECMWF, for a point located offshore the western coast Portugal, on the edge of the continental platform, at $10^{\circ} \mathrm{W}$ and $40^{\circ} \mathrm{N}$. In addition, Figure $11 \mathrm{c}$ shows stacks of ambient noise amplitudes recorded across the network for different periods and components of ground motion. For a given period, the temporal variation of noise amplitudes is identical on all three components of ground motion. Figure 11 highlights one of the strongest peaks of seismic noise in our dataset, which was clearly recorded across all periods of ground motion, from 0.3 to $100 \mathrm{~s}$. This peak occured when a high-amplitude LP oceanic storm hit the coast of Portugal.

Figure 11 is a frame of (E) animation S1. The animation shows the evolution of ocean conditions compared to stacks of seismic noise amplitudes, in steps of $6 \mathrm{hrs,} \mathrm{from} 2010$ to 2012. The animation shows that microseismic noise amplitudes recorded in Portugal are in general very responsive to nearby ocean conditions. (E) Figure S5a shows the evolution of noise amplitudes in the microseismic band, as well as SWH and MWP at the same reference point chosen previously $\left(10^{\circ} \mathrm{W}, 40^{\circ} \mathrm{N}\right)$. At first sight, this figure shows that the evolution of microseismic amplitudes is different for the different ground-motion periods of 4, 7, and $17 \mathrm{~s}$. This observation is in agreement with Sergeant et al. (2013), who found that microseisms of different frequencies have different sources. However, a closer observation shows that although the general evolution of noise amplitudes is different for different microseismic periods, several peaks are common to more than one microseismic band. In fact, Figure 11c shows the most distinct peaks of ambient noise appear not only in the microseismic band but also at periods down to $0.3 \mathrm{~s}$ and up to 100 s. Rhie and Romanowicz (2006) had already observed a positive correlation between microseismic and "hum" (240 s) amplitude fluctuations. This observation may indicate that some microseismic sources generate a very broad spectrum of seismic energy. Most, but not all, microseismic noise peaks find a correspondence on local SWH and MWP (E) animation S1). As expected, the MWP offshore Portugal correlates particularly well with LP DF noise stacks (7 s).

\section{Long-Period Noise}

Sorrells (1971) and Sorrells et al. (1971) showed that the wind-pressure field can contribute significantly to LP seismic noise. They proposed that plane pressure waves with amplitudes of $\sim 10 \mathrm{~Pa}$, moving at typical wind speeds, cause vertical Earth motions, thus increasing vertical noise amplitudes. Although the amplitudes of these motions are small, they cause tilts that are responsible for a significant increase of horizontal noise. These disturbances are only felt close to the surface, their amplitudes decaying quickly with depth. Zürn and Widmer (1995) and Beauduin et al. (1996) successfully enhanced the signal-to-noise ratio of seismic records by correcting for atmospheric pressure.

LP noise levels in Portugal vary significantly from site to site (Fig. 8). Above $20 \mathrm{~s}$, vertical noise starts to present a much lower amplitude than horizontal noise (Fig. 8d), in agreement with observations for stations around the world (e.g., Peterson, 1993; Stutzmann et al., 2000; Berger et al., 2004). (E) Figure S5b shows atmospheric pressure and wind intensity at $10^{\circ} \mathrm{W}$ and $40^{\circ} \mathrm{N}$, extracted from ECMWF reanalysis, along with network stacks of LP (100 s) noise amplitudes. A peak-by-peak examination of this figure, or alternatively of (E) animation S1, shows that while some peaks of LP seismic noise find a correspondence in peaks or troughs of atmospheric pressure and/or wind intensity, the correspondence is not unequivocal. It should also be noted that $100 \mathrm{~s}$ vertical noise amplitudes are not as similar to horizontal noise amplitudes as for all other ground-motion periods (Fig. 11).

A number of authors have reported daily cycles of LP noise, which have been associated with temperature fluctuations either by means of thermal convection around the sensor or thermally induced tilts (e.g., Stutzmann et al., 2000; Berger et al., 2004; Díaz et al., 2010). More recently, De Angelis and Bodin (2012) showed that daily variations of LP noise could be caused by ground tilts due to atmospheric pressure-wind fluctuations. LP daily cycles are visible in many of our records, as shown in Figure 7. They occur more frequently on horizontal components and on temporary sites.

Some records of the WILAS dataset show a sharp $12 \mathrm{hr}$ periodicity of $100 \mathrm{~s}$ noise amplitudes. To the best of our knowledge, a similar observation has not been reported before. Figure 12a and 12c shows, respectively, the atmospheric temperature and pressure recorded in Lisbon. The pressure signal, filtered to show only periods shorter than $36 \mathrm{hrs}$, is also shown. The peak-to-peak amplitude of the $12 \mathrm{hr}$ pressure cycle varies between 100 and $150 \mathrm{~Pa}$, while standard atmospheric pressure is on the order of $10^{5} \mathrm{~Pa}$. Figure 12e shows $12 \mathrm{hr}$ cycles on a time series of $100 \mathrm{~s}$ PSD versus time at POLO-Z. Figure $12 \mathrm{~b}, 12 \mathrm{~d}$, and $12 \mathrm{f}$ shows, respectively, the FFTs of air temperature, pressure, and $100 \mathrm{~s}$ PSD for POLO- $Z$ recordings. FFTs of air temperature and pressure were obtained from $2 \mathrm{yr}$ time series sampled hourly, whereas the FFT of $100 \mathrm{~s}$ PSD was obtained from a $3 \mathrm{yr}$ time series sampled every $30 \mathrm{~min}$. Air temperature is dominated by a fluctuation of $24 \mathrm{hrs}$ (or 1.0 cycle per day [cpd]). Air pressure and $100 \mathrm{~s}$ PSD for POLO- $Z$ are dominated by a $12 \mathrm{hr}$ cycle $(2.0 \mathrm{cpd})$, with higher order harmonics also appearing. This variation of LP noise cannot be explained by typical tides, as lunar components are completely absent from the spectra. LP $12 \mathrm{hr}$ cycles of ambient noise can also be seen in spectrogram (Fig. 12h) and PPSD (Fig. 12g) representation. The PPSD does not show a clear bimodal distribution because $12 \mathrm{hr}$ cycles are not always observed. However, a widening of the PPSD distribution around $100 \mathrm{~s}$ is visible. The spectrogram shows that half-day cycles correspond to an increase of seismic noise with respect to the background level and that they affect ground motion most significantly at periods between 100 and $250 \mathrm{~s}$. It should be noted that our best sensors have a flat response only up to $120 \mathrm{~s}$. We computed PSDs using windows of different lengths (56.66 $\mathrm{min}$ ) and overlaps (23.33 $\mathrm{min}$ ) to verify that the $12 \mathrm{hr}$ 
(a)

(c)
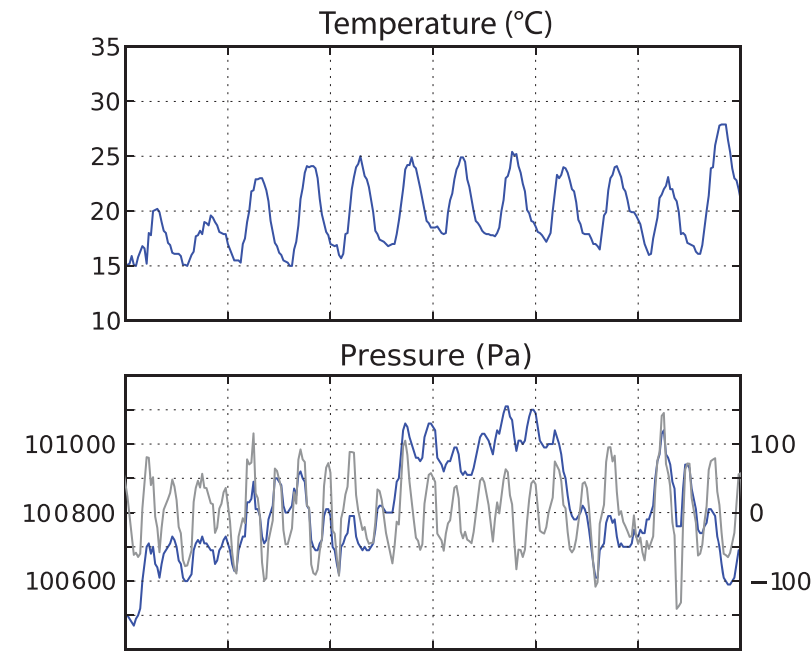

(e)

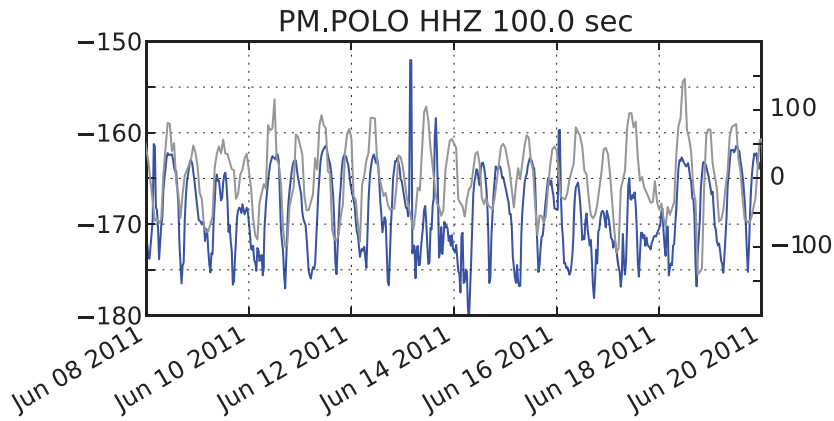

(g)

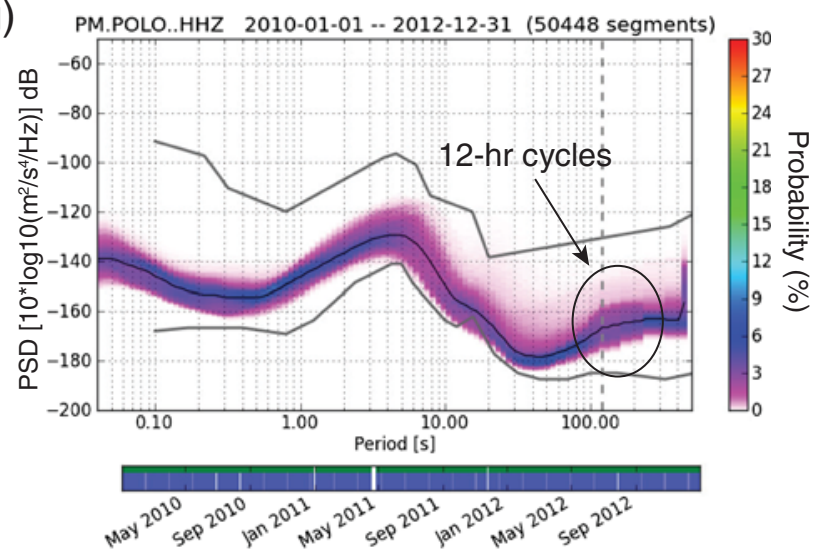

(b)

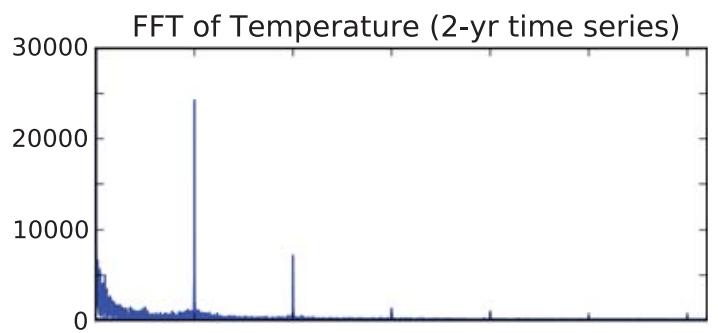

(d)

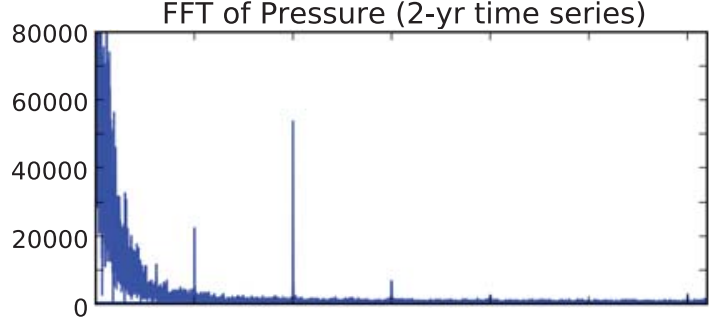

(f)
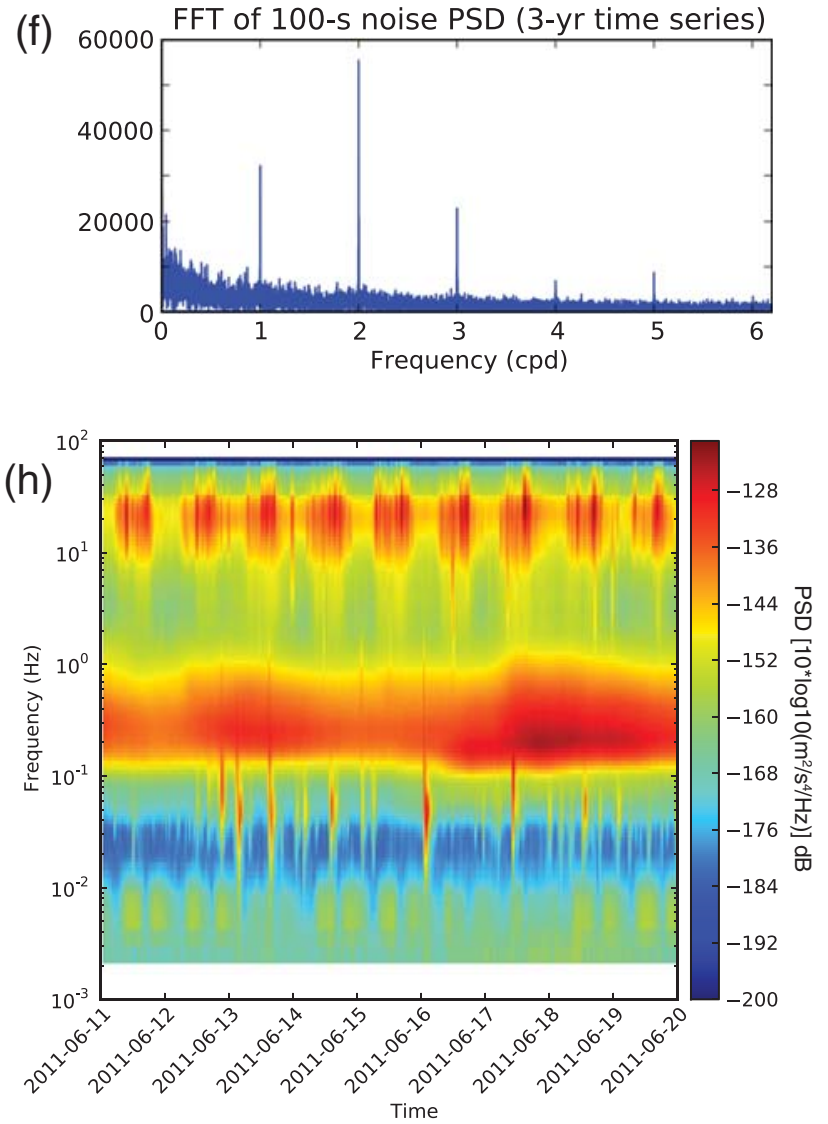

Figure 12. Variation of (a) atmospheric temperature and (c) pressure over 12 consecutive summer days. Atmospheric parameters were recorded hourly at the meteorological station of Lisbon. The gray line shows the pressure filtered so that only periods shorter than $36 \mathrm{hrs}$ are shown (scale on the right). (e) $100 \mathrm{~s}$ PSD versus time for POLO-Z. The gray line shows again the filtered pressure, as plotted in (c). Variations of $100 \mathrm{~s}$ PSD are in phase with changes of atmospheric pressure. Fourier amplitude spectra (FFT) of (b) air temperature, (d) pressure, and (f) $100 \mathrm{~s}$ PSD are also shown. A clear $12 \mathrm{hr}$ cycle (2.0 cycles per day) marks both the $100 \mathrm{~s}$ noise amplitudes and the atmospheric pressure. (g) PPSD of POLO-Z, showing a widening of the PPSD at $100 \mathrm{~s}$. (h) Spectrogram showing that $12 \mathrm{hr}$ cycles on seismic noise amplitudes are most significant at ground-motion periods between 100 and $250 \mathrm{~s}$ (the cut-off instrument of this sensor is $120 \mathrm{~s}$ ). Note that noise rises from the background level to form $12 \mathrm{hr}$ cycles.

cycles do not result from a processing artifact. Although detailed differences exist between PSD time series obtained with different processing parameters, the $12 \mathrm{hr}$ cycles persist with an exact periodicity of $2.0 \mathrm{cpd}$. Not only do $100 \mathrm{~s}$ PSD and air pressure share the same dominant periods, but they are also in phase (Fig. 12e).

The $12 \mathrm{hr}$ cycle of atmospheric pressure is a well-known effect of atmospheric tides that results from an interaction 
(a)

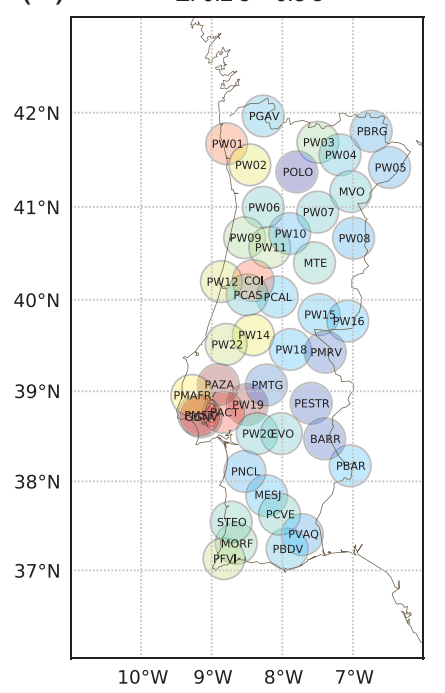

(b)

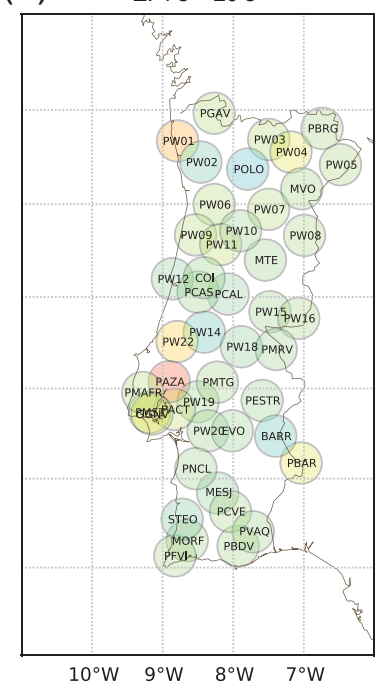

(c)

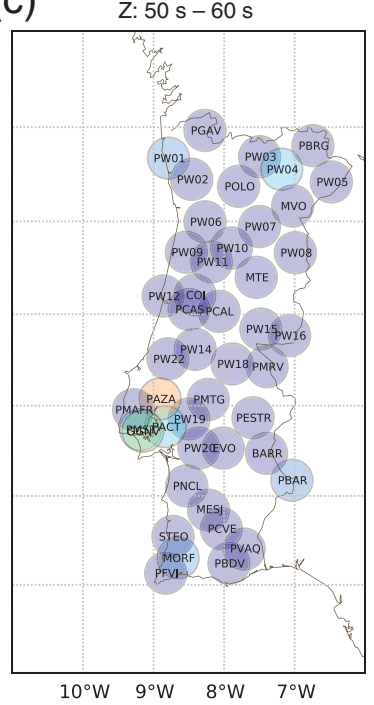

(d)

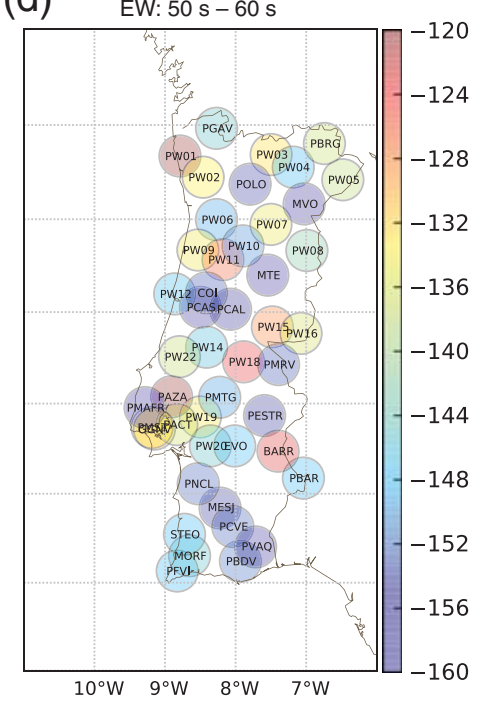

Figure 13. Maps of seismic noise levels recorded during the WILAS experiment. (a) Short-period (0.2-0.5 s) vertical noise. (b) Microseismic (4-20 s) vertical noise. (c) Long-period (50-60 s) vertical noise. (d) Long-period (50-60 s) EW noise. Short-period noise is higher close to the urban centers of Lisbon, Coimbra, and Porto, and along the highly populated northern coast of Portugal. Microseismic noise is fairly homogenous across the network. Long-period vertical noise levels are very low, whereas long-period horizontal noise levels are substantially higher, particularly at temporary sites.

between gravitational and thermal driving forces (Lindzen and Chapman, 1969; Chapman and Lindzen, 1970). To the best of our knowledge, atmospheric pressure is the only environmental parameter to present a dominant frequency of 2.0 cpd. The $12 \mathrm{hr}$ pressure cycle is stronger during summer, and its amplitude increases with altitude and with proximity to the equator (e.g., Covey et al., 2010, and references therein). A preliminary inspection of our dataset reveals that $12 \mathrm{hr}$ cycles of $100 \mathrm{~s}$ PSDs occur more frequently during the summer and at high altitude stations, in good agreement with the conditions under which the $12 \mathrm{hr}$ pressure cycle is expected to be stronger. They are most often visible in vertical records, although they can also be found on horizontal records, particularly at temporary sites, which are poorly insulated from the surrounding environment.

One curious observation is that although $100 \mathrm{~s}$ noise amplitudes closely follow the $12 \mathrm{hr}$ pressure cycle, they are not as responsive to LP (several days long) atmospheric pressure variations. A particular sensitivity to the $12 \mathrm{hr}$ cycle seems to exist, which may implicate a resonance mechanism. The mechanism by which seismometers respond to small pressure variations on the order of $100 \mathrm{~Pa}$ is unclear. Although $12 \mathrm{hr}$ noise cycles appear to be associated with atmospheric tides, it is unclear at this point whether they reflect a purely instrumental response or an actual solid Earth deformation process. A more detailed study of these $12 \mathrm{hr}$ cycles of $100 \mathrm{~s}$ PSDs is left for future work.

\section{Ambient Noise Maps}

Figure 13a shows the vertical SP $(0.2-0.5 \mathrm{~s})$ noise distribution. Higher noise levels are recorded close to the urban centers of Lisbon, Coimbra, and Porto and generally along the northern coast of Portugal, where population density is high. Figure 13b shows the vertical microseismic (4-20 s) noise distribution, with very homogeneous noise levels across the whole network. LP (50-60 s) vertical noise levels are shown in Figure 13c. Noise is very low across the network, with a few temporary sites displaying higher noise amplitudes. For comparison, Figure 13d shows LP east-west noise levels, which are much higher than vertical LP noise levels, particularly at temporary sites. Stations PW01, PAZA, and BARR have particularly high noise levels across all periods of ground motion, which may reflect poor site conditions or strong site effects.

Figure 14a is a gridded map of background seismic noise covering the whole Iberian Peninsula and northern Morocco. The map is computed from vertical records obtained at permanent networks and at the temporary WILAS and TopoIberia-IberArray deployments. Mean noise level is calculated for each station in a wide period band, from 0.1 to $60 \mathrm{~s}$, and then interpolated to a $5 \times 5 \mathrm{~min}$ (approximately $10 \mathrm{~km} \times 10 \mathrm{~km}$ ) grid using a classical near-neighbor algorithm. The general distribution of seismic noise correlates well with major geologic features, in particular with the distribution of large sedimentary basins. The largest sedimentary basin in Portugal, the LTV, appears as a high noise region (also identified in Fig. 9). The Guadalquivir and Gharb basins, both major sedimentary regional units, are clearly identified on both sides of the Gulf of Cadiz (north and south, respectively). The Tagus and Duero basins, both of which are regions of thick sedimentary cover, are outlined near central Iberia. To the northeast, the Ebro basin can also be identified by its relatively high noise level. The correspondence between sedimentary basins and high noise levels is 
(a)
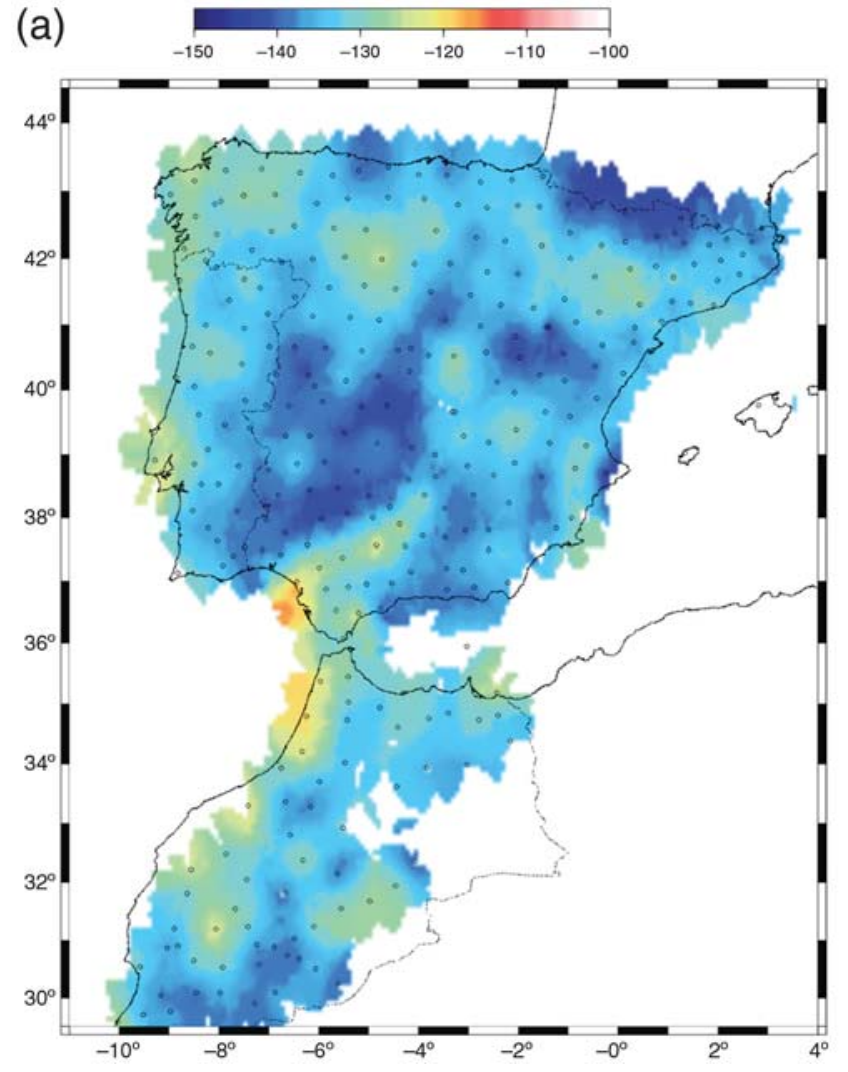

(b)

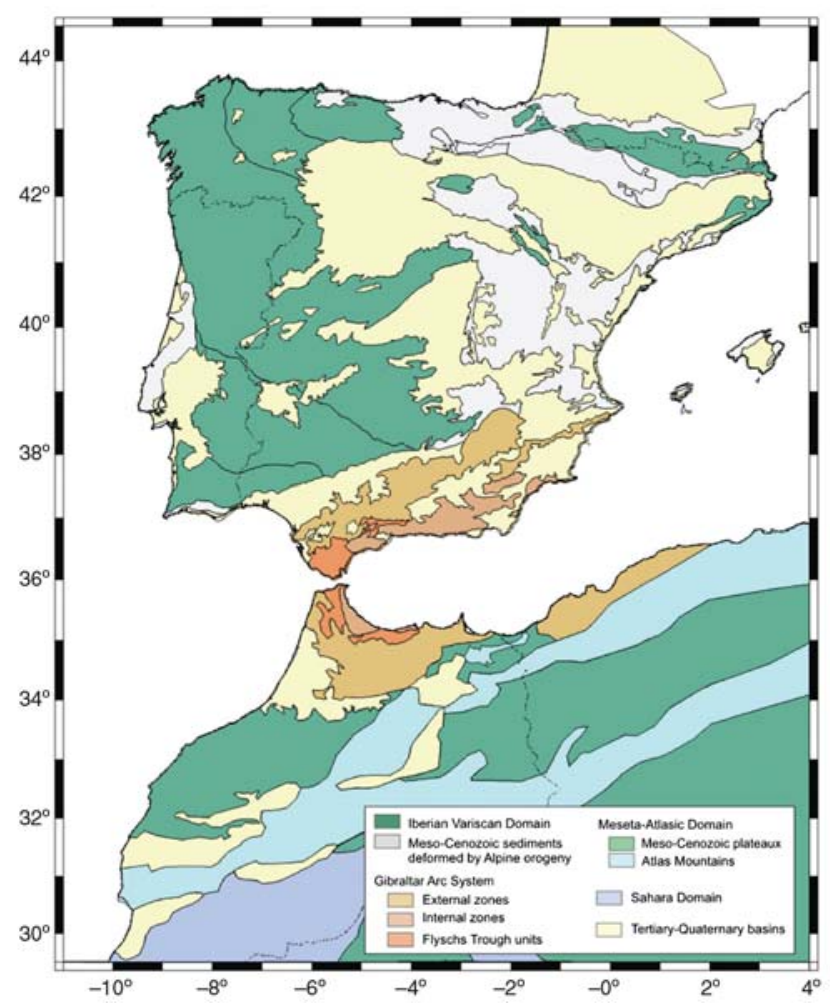

Figure 14. (a) Noise levels observed in Iberia and northern Morocco between 0.1 and $60 \mathrm{~s}$ on vertical recordings, and (b) a simplified tectonic map of Iberia. The central Iberian massif presents low noise amplitudes, whereas sedimentary basins show high noise amplitudes.

likely to result from the combined effects of geology and human activity. The latter tends to be more significant in basins. In contrast, hard-rock regions like the CIM present lower noise levels. This separation between outcrops of the CIM and basins is consistent with previous studies based on seismic ambient noise (Villaseñor et al., 2007; Silveira et al., 2013). Northwest Iberia and in general the Atlantic coast are noisier than strictly expected from a geologic point of view, probably due to the stronger microseismic energy reaching coastal stations.

\section{Time Periods of Anomalous Instrumental Response}

When plotting PSDs at given ground-motion periods versus time, we noticed anomalies in instrumental response that most noticeably affected LP amplitudes (Fig. 15). These anomalies can last days, weeks, or even months, they appear at both temporary and permanent stations, and they often do not affect SP amplitudes. Ekström et al. (2006) and Ringler et al. (2010) had already reported the existence of timedependent errors in LP gains of stations of the GSN. GSN stations are equipped with STS-1 sensors, which are very high-performance instruments. The electronic components of STS-1 seismometers are inside a box that is separate from the actual sensor, which makes the instrument more prone to changes in response than modern sensors with internal electronics, like the ones used in our deployment. Ekström et al.
(2006) systematically compared observed and synthetic LP seismograms for approximately 600 large earthquakes and reported that changes in gain were larger at LPs, which we also observe in our dataset. They suggested that a possible explanation for this behavior was the deterioration of electronic components in the system.

We prefer to call this occurrence a change of instrumental response rather than a change of instrumental gain, as the gain should affect all frequencies of ground motion equally. Changes in LP response of the WILAS stations sometimes occur instantaneously and sometimes occur gradually (Fig. 15). Figure 15a shows a step-like change in LP response that occurred when lightning struck close to the station. Notice that SP amplitudes were not affected. One could conceive that the lightning caused a temporary change of the seismometer into SP mode. Figure 15b shows a station with repeated drifts in LP response. Whenever LP response anomalies became significant, masses were remotely locked, unlocked, and then recentered. This procedure brought the LP response back to their normal value. After the LP response drifted a few times, the sensor failed and had to be replaced (15 February 2012). Even after sensor replacement, LP response kept drifting, which eventually led to another sensor replacement on 12 October 2013.

Monitoring PSDs versus time at chosen periods is useful to detect and either exclude or characterize and correct LP 

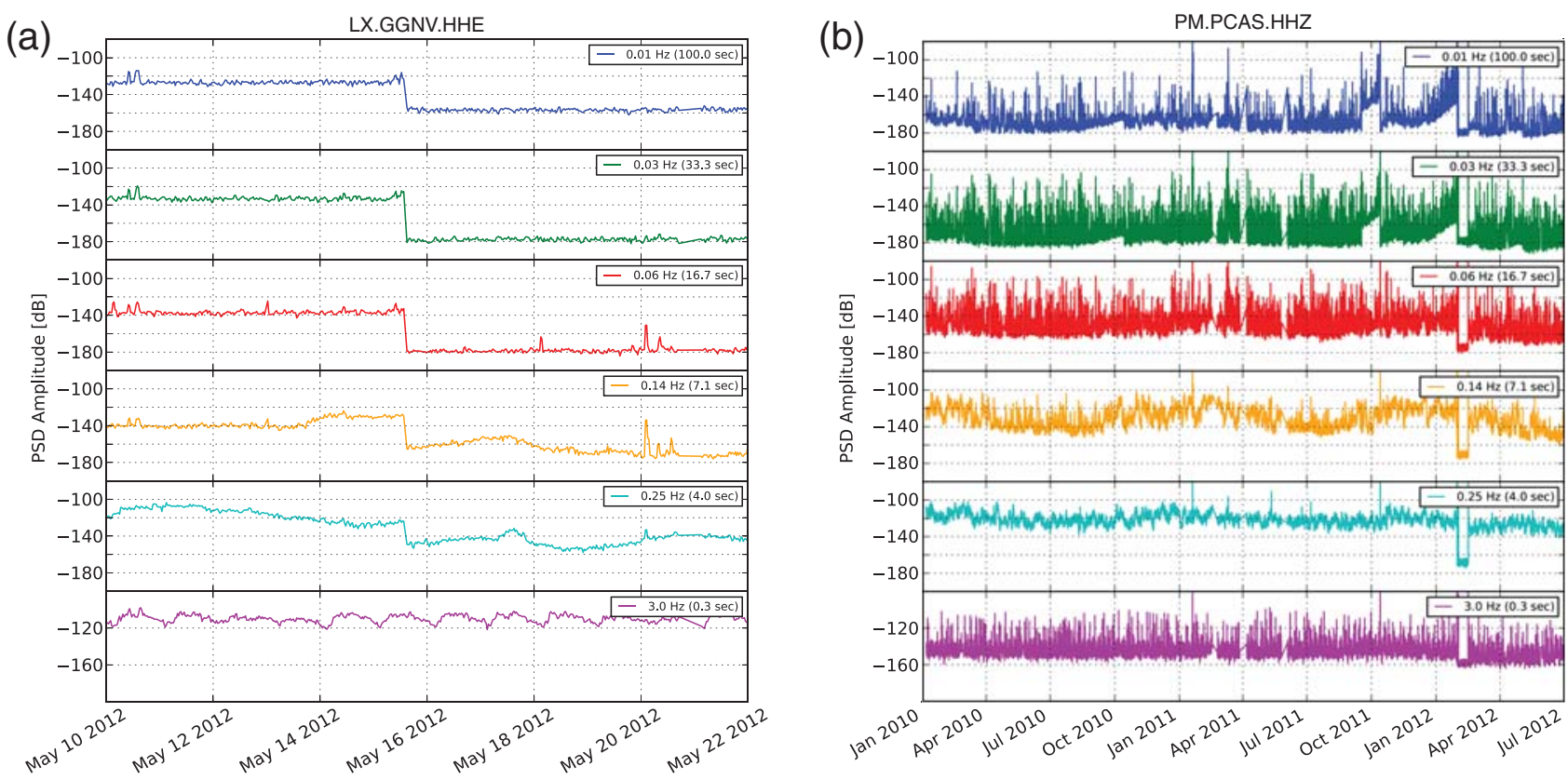

(c)

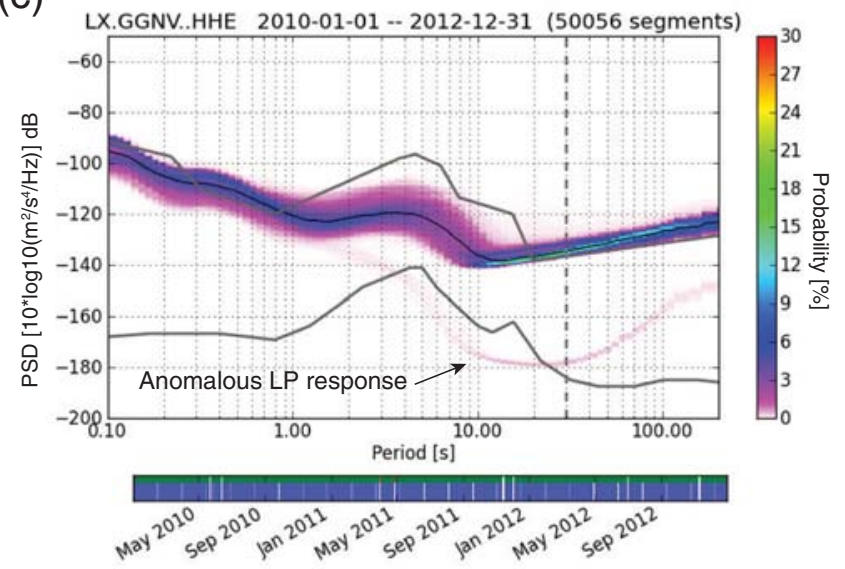

(d)

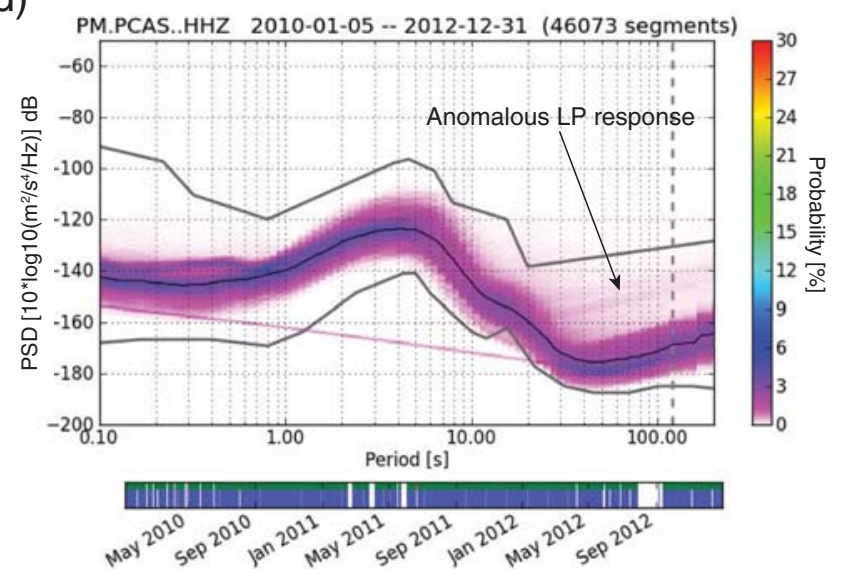

Figure 15. Time evolution of PSDs at chosen ground-motion periods showing times of abnormal LP responses. (a) Station GGNV-E. Sensor response is suddenly altered on 15 May 2012 for ground-motion periods of 4, 7, 17, 33, and $100 \mathrm{~s}$. No change affects SP (0.3 s) data. (b) Station PCAS-Z. The LP response is gradually altered between September 2011 and February 2012. (c,d) PPSDs of GGNV-E and PCAS-Z showing periods of anomalous LP response. Dashed gray lines show the instrumental cut-off frequencies.

responses. In our experience, such detection and correction is critical for studies that use LP amplitudes, such as ambient noise studies and waveform modeling.

\section{Conclusions}

The WILAS experiment densely covered Portugal with BB seismic stations during a $2 \mathrm{yr}$ period between 2010 and 2012. The experiment encompassed the permanent stations of the national seismological survey (IPMA), other permanent stations run by universities and research centers (IDL/Universidade de Lisboa, Centro de Recursos Naturais e Ambiente/Instituto Superior Técnico, Centro de Geofísica de Évora/University of Évora, Centro de Geofísica/
Universidade de Coimbra), and 20 temporary stations. The experiment was designed to overlap in time with the TopoIberia-IberArray deployment in the neighbor countries of Spain and northern Morocco.

Sensor orientation was checked a posteriori based on the analysis of teleseismic $P$ waves. We were able to confidently assess the orientation of 34 sensors. Among these, more than half showed reliable orientations with deviations of less than $5^{\circ}$ from the geographic north. The analysis allowed us to correct data headers and in two extreme cases to actually correct data of sensors that had been incorrectly oriented at installation.

We characterized ambient seismic noise using the PPSD technique proposed by McNamara and Buland (2004). We 
found the diversity of sensors and deployment conditions affected noise amplitudes only at LPs ( $>10 \mathrm{~s}$ ). Temporary sites were shown to present very similar noise levels to permanent sites, except on horizontal LP recordings, which had higher noise levels. This behavior is well known and generally attributed to the poorer insulation of temporary sites from atmospheric conditions (Wilson et al., 2002; Díaz et al., 2010).

SP noise often showed daily cycles, mostly due to cultural noise. This hypothesis is confirmed by the geographical distribution of SP noise, with the noisiest stations close to urban centers, and by the diminishing of SP noise levels during weekends and at night.

Median noise levels recorded at different stations are very similar in the microseismic band, particularly in the vertical component. In fact, the similarity of median noise levels in this band was so strong that in preliminary quality control we were able to detect erroneous instrumental gains based on deviations from the ensemble noise level. Outside the microseismic band, noise levels at different stations diverge. The ratio of DF amplitudes recorded on vertical and horizontal components is strongly correlated with the type of soil on which the stations are located, with stations on sediments recording higher horizontal noise amplitudes and stations on hard rock recording higher vertical noise amplitudes. Microseisms show a strong seasonality, with the strongest seasonality at ground-motion periods of 8 and $17 \mathrm{~s}$. Although the $17 \mathrm{~s}$ seasonality peak is coincident with the SF peak in our dataset, the $8 \mathrm{~s}$ seasonality peak has a period larger than DF peaks on our data. This observation confirms the notion that the seasonality of DF microseisms is dominated by LP swell generated during winter storms. (E) Animation S1 shows stacks of ambient noise amplitudes recorded across the whole network, along with evolving oceanic and atmospheric conditions. This animation shows that the amplitudes of microseismic noise in our data are related to ocean wave height and MWP offshore of Portugal. A close look at the evolution of noise stacks across the network also reveals that the strongest microseismic peaks are visible across the whole range of ground-motion periods, from 0.3 to $100 \mathrm{~s}$.

In general, ambient noise amplitudes at a given period are very similar on the three components of ground motion. However, at LPs vertical amplitudes do not follow horizontal amplitudes so closely. We find that some peaks in LP noise amplitudes match peaks or troughs of atmospheric and/or wind intensity; however, a relation between LP noise and atmospheric variables is not evident.

In some time intervals and at some stations, we observe sharp $12 \mathrm{hr}$ cycles of LP noise (100-s PSD), which to the best of our knowledge have not been reported before. This signal is most visible during the summer and at high-altitude stations. The $12 \mathrm{hr}$ cycle of LP noise amplitudes seems to track variations of atmospheric pressure. Although we have established that this signal is not a processing artifact, it is unclear at this point whether it is an instrumental artifact or an actual record of solid Earth deformation. Future work will address this observation in detail.
Finally, we reported anomalous changes in LP sensor response. These changes can last anywhere from minutes to months, are normally stronger at longer periods, and seem to be associated with instrumental malfunctioning. Response changes can be easily monitored by plotting the time evolution of ambient noise PSD at specific ground-motion periods.

\section{Data and Resources}

Permanent broadband stations running in Portugal are owned and/or operated by Instituto Português do Mar e da Atmosfera (PM), GEOFON (GE), Instituto Superior Técnico (IP), Instituto Geofísico Dom Luiz (LX), Centro de Geofísica da Universidade de Coimbra (SS), and Centro de Geofísica da Universidade de Évora (WM). The temporary WILAS deployment, which used instrumentation from the Geophysical Instrument Pool of GFZ Potsdam (GIPP), was registered under International Federation of Digital Seismograph Networks network code 8A. Its data will be openly available at international data centers after June 2016. Data from the Topolberia-IberArray experiment and from permanent networks in Spain and Morocco, managed by Instituto Geográfico Nacional, Real Observatório de la Armada, and Instituto Andaluz de Geofísica, were used to calculate the noise map presented in Figure 14. Reanalyses of atmospheric and ocean conditions were obtained from the European Center for Medium Range Weather Forecasting. Atmospheric pressure and temperature recorded in Lisbon were kindly made available by Pedro Miranda, Instituto Dom Luiz.

We used the following softwares for data processing and figure plotting: Generic Mapping Tools (Wessel and Smith, 1998); Python, including NumPy, SciPy, MatPlotLib, Basemap and ObsPy (Beyreuther et al., 2010); and PQLX.

\section{Acknowledgments}

The authors are grateful to all West Iberia Lithosphere and Asthenosphere Structure (WILAS) field and data center staff, without whom this experiment would not have been possible. We are also grateful to Toshiro Tanimoto, Pedro Miranda, Karl-Heinz Jaeckel, and Graça Silveira for insightful discussions. Simone Marzorati and two anonymous reviewers contributed to improving the manuscript with thoughtful comments. This research was supported by Fundação para a Ciência e Tecnologia through projects WILAS (PTDC/CTE-GIX/097946/2008), QuakeLoc-PT (PTDC/GEO-FIQ/3522/ 2012), and SCENE (PTDC/CTE-GIX/103032/2008), and by the European Commission FP7 project NERA (Network of European Research Infrastructures for Earthquake Risk Assessment and Mitigation, GA-262330). This is a contribution to PEST-OE/CTE/LA0019/2011 (IDL). The first author acknowledges a Marie Curie International Reintegration Grant from the European Commission, FP7 (PIRG03-GA-2008-230922).

\section{References}

Ardhuin, F., A. Balanche, E. Stutzmann, and M. Obrebski (2012). From seismic noise to ocean wave parameters: General methods and validation, J. Geophys. Res. 117, no. C5, doi: 10.1029/2011JC007449.

Beauduin, R., P. Lognonné, J. P. Montagner, S. Cacho, J. F. Karczewski, and M. Morand (1996). The effects of the atmospheric pressure changes on seismic signals or how to improve the quality of a station, Bull. Seismol. Soc. Am. 86, no. 6, 1760-1769. 
Becker, J. J., D. T. Sandwell, W. H. F. Smith, J. Braud, B. Binder, J. Depner, D. Fabre, J. Factor, S. Ingalls, S-H. Kim, R. Ladner, K. Marks, S. Nelson, A. Pharaoh, R. Trimmer, J. Von Rosenberg, G. Wallace, and P. Weatherall (2009). Global bathymetry and elevation data at 30 arc seconds resolution: SRTM30+, Mar. Geodes. 32, no. 4, 355-371, doi: 10.1080/01490410903297766.

Berger, J., P. Davis, and G. Ekström (2004). Ambient earth noise: A survey of the Global Seismographic Network, J. Geophys. Res. 109, no. B11, doi: 10.1029/2004JB003408.

Besana-Ostman, G. M., S. P. Vilanova, E. S. Nemser, A. Falcao-Flor, S. Heleno, H. Ferreira, and J. D. Fonseca (2012). Large Holocene earthquakes in the Lower Tagus Valley fault zone, central Portugal, Seismol. Res. Lett. 83, no. 1, 67-76, doi: 10.1785/gssrl.83.1.67.

Beyreuther, M., R. Barsch, L. Krischer, T. Megies, Y. Behr, and J. Wassermann (2010). Obspy: A Python toolbox for seismology, Seismol. Res. Lett. 81, no. 3, 530-533, doi: 10.1785/gssrl.81.3.530.

Bezzeghoud, M., C. Adam, E. Buforn, J. Borges, and B. Caldeira (2014). Seismicity along the Azores-Gibraltar region and global plate kinematics, J Seismol. 18, 205-220, doi: 10.1007/s10950-013-9416-x.

Borges, J., A. J. S. Fitas, M. Bezzeghoud, and P. Teves-Costa (2001). Seismotectonics of Portugal and its adjacent Atlantic area, Tectonophysics 331, no. 4, 373-387, doi: 10.1016/S0040-1951(00)00291-2.

Bromirski, P. D. (2001). Vibrations from the "perfect storm," Geochem. Geophys. Geosyst. 2, no. 7, doi: 10.1029/2000GC000119.

Bromirski, P. D., and F. K. Duennebier (2002). The near-coastal microseism spectrum: Spatial and temporal wave climate relationships, J. Geophys. Res. 107, no. B8, doi: 10.1029/2001JB000265.

Bromirski, P. D., F. K. Duennebier, and R. A. Stephen (2005). Mid-ocean microseisms, Geochem. Geophys. Geosyst. 6, no. 4, doi: 10.1029/ 2004GC000768.

Buforn, E., C. S. de Galdeano, and A. Udías (1995). Seismotectonics of the Ibero-Maghrebian region, Tectonophysics 248, nos. 3/4, 247-261, doi: 10.1016/0040-1951(94)00276-F.

Cabral, J., C. Moniz, J. Batlló, P. Figueiredo, J. Carvalho, L. Matias, P. Teves-Costa, R. Dias, and N. Simão (2013). The 1909 Benavente (Portugal) earthquake: Search for the source, Nat. Hazards 69, no. 2, 1211-1227, doi: 10.1007/s11069-011-0062-8.

Carvalho, J., T. Rabeh, R. Dias, R. Dias, C. Pinto, T. Oliveira, T. Cunha, and J. Borges (2014). Tectonic and neotectonic implications of a new basement map of the Lower Tagus Valley, Portugal, Tectonophysics 617, 88-100, doi: 10.1016/j.tecto.2014.01.017.

Casas-Sainz, A., and G. de Vicente (2009). On the tectonic origin of Iberian topography, Tectonophysics 474, nos. 1/2, 214-235, doi: 10.1016/ j.tecto.2009.01.030.

Chapman, S., and R. Lindzen (1970). The solar daily atmospheric oscillations as revealed by meteorological data, in Atmospheric Tides, Springer, Netherlands, 24-65, doi: 10.1007/978-94-010$3399-2$.

Cloetingh, S., E. Burov, F. Beekman, B. Andeweg, P. A. M. Andriessen, D. Garcia-Castellanos, G. de Vicente, and R. Vegas (2002). Lithospheric folding in Iberia, Tectonics 21, no. 5, 5-1-5-26, doi: 10.1029/2001TC901031.

Covey, C., A. Dai, D. Marsh, and R. S. Lindzen (2010). The surface-pressure signature of atmospheric tides in modern climate models, J. Atmos. Sci. 68, no. 3, 495-514, doi: 10.1175/2010JAS3560.1.

Cunha, T. A., L. M. Matias, P. Terrinha, A. M. Negredo, F. Rosas, R. M. S. Fernandes, and L. M. Pinheiro (2012). Neotectonics of the SW Iberia margin, Gulf of Cadiz and Alboran Sea: A reassessment including recent structural, seismic and geodetic data, Geophys. J. Int. 188, no. 3, 850-872, doi: 10.1111/j.1365-246X.2011.05328.x.

De Angelis, S., and P. Bodin (2012). Watching the wind: Seismic data contamination at long periods due to atmospheric pressure-field-induced tilting, Bull. Seismol. Soc. Am. 102, no. 3, 1255-1265, doi: 10.1785/ 0120110186.

Dias, R., and A. Ribeiro (1995). The Ibero-Armorican arc: A collision effect against an irregular continent? Tectonophysics 246, nos. 1/3, 113-128, doi: 10.1016/0040-1951(94)00253-6.
Díaz, J., and J. Gallart (2009). Crustal structure beneath the Iberian Peninsula and surrounding waters: A new compilation of deep seismic sounding results, Phys. Earth Planet. Int. 173, nos. 1/2, 181-190, doi: 10.1016/j.pepi.2008.11.008.

Díaz, J., J. Gallart, D. Córdoba, L. Senos, L. Matias, E. Suriñach, A. Hirn, and P. Maguire (1993). A deep seismic sounding investigation of lithospheric heterogeneity and anisotropy beneath the Iberian Peninsula, Tectonophysics 221, no. 1, 35-51, doi: 10.1016/0040-1951(93) 90026-G.

Díaz, J., A. Villaseñor, J. Morales, A. Pazos, D. Córdoba, J. Pulgar, J. L. García-Lobón, M. Harnafi, R. Carbonell, J. Gallart et al. (2010). Background noise characteristics at the IberArray broadband seismic network, Bull. Seismol. Soc. Am. 100, no. 2, 618-628, doi: 10.1785/0120090085.

Ekström, G., and R. W. Busby (2008). Measurements of seismometer orientation at USArray transportable array and backbone stations, Seismol. Res. Lett. 79, no. 4, 554-561, doi: 10.1785/gssrl.79.4.554.

Ekström, G., C. A. Dalton, and M. Nettles (2006). Observations of time-dependent errors in long-period instrument gain at global seismic stations, Seismol. Res. Lett. 77, no. 1, 12-22, doi: 10.1785/ gssrl.77.1.12.

Evangelidis, C. P., and N. S. Melis (2012). Ambient noise levels in Greece as recorded at the Hellenic Unified Seismic Network, Bull. Seismol. Soc. Am. 102, no. 6, 2507-2517, doi: 10.1785/0120110319.

Fernandes, R. M. S., B. A. C. Ambrosius, R. Noomen, L. Bastos, M. J. R. Wortel, W. Spakman, and R. Govers (2003). The relative motion between Africa and Eurasia as derived from ITRF2000 and GPS data, Geophys. Res. Lett. 30, no. 16, doi: 10.1029/2003GL017089.

Fonseca, J. F. B. D., and S. P. Vilanova (2010). The 23 April 231909 Benavente (Portugal) M 6.3 earthquake, Seismol. Res. Lett. 81, no. 3, 534-536, doi: 10.1785/gssrl.81.3.534.

Fukao, Y. (1973). Thrust faulting at a lithospheric plate boundary the Portugal earthquake of 1969, Earth Planet. Sci. Lett. 18, no. 2, 205-216, doi: 10.1016/0012-821X(73)90058-7.

García, A., R. Ortiz, J. M. Marrero, N. Sánchez, J. Vila, A. M. Correig, R. Marcià, R. Sleeman, and M. Tárraga (2006). Monitoring the reawakening of Canary Islands' Teide Volcano, Eos Trans. AGU 87, no. 6, 61-65, doi: 10.1029/2006EO060001.

García-Navarro, E., and C. Fernández (2004). Final stages of the Variscan orogeny at the southern Iberian massif: Lateral extrusion and rotation of continental blocks, Tectonics 23, no. 6, doi: 10.1029/2004TC001646.

Grecu, B., C. Neagoe, and D. Tataru (2012). Seismic noise characteristics at the Romanian broadband seismic network, J. Earthq. Eng. 16, no. 5, 644-661, doi: 10.1080/13632469.2011.642931.

Grigoli, F., S. Cesca, T. Dahm, and L. Krieger (2012). A complex linear least-squares method to derive relative and absolute orientations of seismic sensors, Geophys. J. Int. 188, no. 3, 1243-1254, doi: 10.1111/j.1365-246X.2011.05316.x.

Hasselmann, K. (1963). A statistical analysis of the generation of microseisms, Rev. Geophys. 1, no. 2, 177-210, doi: 10.1029/ RG001i002p00177.

Haubrich, R. A., and K. McCamy (1969). Microseisms: Coastal and pelagic sources, Rev. Geophys. 7, no. 3, 539-571, doi: 10.1029/ RG007i003p00539.

Hirn, A., L. Senos, M. Sapin, and L. M. Victor (1982). High to low velocity succession in the upper crust related to tectonic emplacement: Tras os Montes-Galicia (Iberia), Brittany and Limousin (France), Geophys. J. Int. 70, no. 1, 1-10, doi: 10.1111/j.1365-246X.1982.tb06387.x.

Johnston, A. C. (1996). Seismic moment assessment of earthquakes in stable continental regions-III. New Madrid 1811-1812, Charleston 1886 and Lisbon 1755, Geophys. J. Int. 126, no. 2, 314-344, doi: 10.1111/j.1365-246X.1996.tb05294.x.

Lindzen, R., and S. Chapman (1969). Atmospheric tides, Space Sci. Rev. 10, no. $1,3-188$, doi: $10.1007 / \mathrm{BF} 00171584$.

Longuet-Higgins, M. S. (1950). A theory of the origin of microseisms, Phil. Trans. Roy. Soc. Lond. A 243, no. 857, 1-35, doi: 10.1098/ rsta.1950.0012. 
Marzorati, S., and D. Bindi (2006). Ambient noise levels in north central Italy, Geochem. Geophys. Geosyst. 7, no. 9, doi: 10.1029/ 2006GC001256.

McNamara, D. E., and R. P. Buland (2004). Ambient noise levels in the continental United States, Bull. Seismol. Soc. Am. 94, no. 4, 1517-1527.

Monna, S., G. B. Cimini, C. Montuori, L. Matias, W. H. Geissler, and P. Favali (2013). New insights from seismic tomography on the complex geodynamic evolution of two adjacent domains: Gulf of Cadiz and Alboran Sea, J. Geophys. Res. doi: 10.1029/2012JB009607.

Narciso, J., S. Vilanova, I. Lopes, C. S. Oliveira, J. Carvalho, C. Pinto, J. F. Borges, and E. S. Nemser (2012). Developing a site-conditions map for seismic hazard assessment in Portugal, in 15th World Conference on Earthquake Engineering, Lisbon, Portugal, 24-28 September 2012, 4864.

Onézime, J., J. Charvet, M. Faure, J.-L. Bourdier, and A. Chauvet (2003). A new geodynamic interpretation for the south Portuguese zone (SW Iberia) and the Iberian pyrite belt genesis, Tectonics 22, no. 4, doi: 10.1029/2002TC001387.

Palomeras, I., S. Thurner, A. Levander, K. Liu, A. Villasenor, R. Carbonell, and M. Harnafi (2014). Finite-frequency Rayleigh wave tomography of the western Mediterranean: Mapping its lithospheric structure, Geochem. Geophys. Geosyst. doi: 10.1002/2013GC004861.

Peterson, J. (1993). Observations and modeling of seismic background noise, U.S. Geol. Surv. Open-File Rept. 93-322.

Press, W. H., S. A. Teukolsky, W. T. Vetterling, and B. P. Flannery (2007). Numerical Recipes: The Art of Scientific Computing, Third Ed., Cambridge University Press, New York.

Rastin, S. J., C. P. Unsworth, K. R. Gledhill, and D. E. McNamara (2012). A detailed noise characterization and sensor evaluation of the North Island of New Zealand using the PQLX data quality control system, Bull. Seismol. Soc. Am. 102, no. 1, 98-113, doi: 10.1785/0120110064.

Rhie, J., and B. Romanowicz (2006). A study of the relation between ocean storms and the Earth's hum, Geochem. Geophys. Geosyst. 7, no. 10, doi: 10.1029/2006GC001274.

Ringler, A. T., L. S. Gee, C. R Hutt, and D. E. McNamara (2010). Temporal variations in global seismic station ambient noise power levels, Seismol. Res. Lett. 81, no. 4, 605-613, doi: 10.1785/gssrl.81.4.605.

Salah, M. K., S. J. Chang, and J. F. B. D. Fonseca (2011). Crustal structure beneath the Lower Tagus Valley, southwestern Iberia using joint analysis of teleseismic receiver functions and surface-wave dispersion, Geophys. J. Int. 184, no. 2, 919-933, doi: 10.1111/j.1365246X.2010.04891.x.

Schulte-Pelkum, V., P. S. Earle, and F. L Vernon (2004). Strong directivity of ocean-generated seismic noise, Geochem. Geophys. Geosyst. 5, no. 3, doi: $10.1029 / 2003$ GC000520.

Sergeant, A., E. Stutzmann, A. Maggi, M. Schimmel, F. Ardhuin, and M. Obrebski (2013). Frequency-dependent noise sources in the North Atlantic Ocean, Geochem. Geophys. Geosyst. doi: 10.1002/ 2013GC004905.

Serpelloni, E., G. Vannucci, S. Pondrelli, A. Argnani, G. Casula, M. Anzidei, P. Baldi, and P. Gasperini (2007). Kinematics of the western Africa-Eurasia plate boundary from focal mechanisms and GPS data, Geophys. J. Int. 169, no. 3, 1180-1200, doi: 10.1111/j.1365246X.2007.03367.x.

Sheen, D.-H., J. Shin, and T.-S. Kang (2009). Seismic noise level variation in South Korea, Geosci. J. 13, no. 2, 183-190, doi: 10.1007/s12303-0090018-0.

Silveira, G., N. A. Dias, and A. Villaseñor (2013). Seismic imaging of the western Iberian crust using ambient noise: Boundaries and internal structure of the Iberian massif, Tectonophysics 589, 186-194, doi: 10.1016/j.tecto.2012.12.025.

Simancas, J. F., R. Carbonell, F. González Lodeiro, A. Pérez Estaún, C. Juhlin, P. Ayarza, A. Kashubin, A. Azor, D. Martínez Poyatos, G. R. Almodóvar et al. (2003). Crustal structure of the transpressional Variscan orogen of SW Iberia: SW Iberia deep seismic reflection profile (IBERSEIS), Tectonics 22, no. 6, doi: 10.1029/ 2002 TC001479.
Simancas, J., D. Poyatos, I. Expósito, A. Azor, and F. Lodeiro (2001). The structure of a major suture zone in the SW Iberian massif: The Ossa-Morena/central Iberian contact, Tectonophysics 332, nos. 1/2, 295-308, doi: 10.1016/S0040-1951(00)00262-6.

Sleeman, R., and J. Vila (2007). Towards an automated quality control manager for the Virtual European Broadband Seismograph Network (VESBN), ORFEUS Newsletter 7, no. 1, January.

Sorrells, G. G. (1971). A preliminary investigation into the relationship between long-period seismic noise and local fluctuations in the atmospheric pressure field, Geophys. J. Roy. Astron. Soc. 26, nos. 1/ 4, 71-82, doi: 10.1111/j.1365-246X.1971.tb03383.x.

Sorrells, G. G., J. A. McDonald, Z. A. Der, and E. Herrin (1971). Earth motion caused by local atmospheric pressure changes, Geophys. J. Roy. Astron. Soc. 26, nos. 1/4, 83-98, doi: 10.1111/j.1365246X.1971.tb03384.x.

Stich, D., J. Batlló, R. Macià, P. Teves-Costa, and J. Morales (2005). Moment tensor inversion with single-component historical seismograms: The 1909 Benavente (Portugal) and Lambesc (France) earthquakes, Geophys. J. Int. 162, no. 3, 850-858, doi: 10.1111/j.1365246X.2005.02680.x.

Stutzmann, E., G. Roult, and L. Astiz (2000). GEOSCOPE station noise levels, Bull. Seismol. Soc. Am. 90, no. 3, 690-701.

Tanimoto, T. (2007a). Excitation of normal modes by non-linear interaction of ocean waves, Geophys. J. Int. 168, no. 2, 571-582, doi: 10.1111/ j.1365-246X.2006.03240.x.

Tanimoto, T. (2007b). Excitation of microseisms, Geophys. Res. Lett. 34, no. 5, doi: 10.1029/2006GL029046.

Tanimoto, T., T. Yano, and T. Hakamata (2013). An approach to improve Rayleigh-wave ellipticity estimates from seismic noise: Application to the Los Angeles basin, Geophys. J. Int. 193, no. 1, 407-420, doi: $10.1093 / \mathrm{gji} / \mathrm{ggs} 123$.

Teves-Costa, P., and J. Batlló (2011). The 23 April 1909 Benavente earthquake (Portugal): Macroseismic field revision, J. Seismol. 15, no. 1, 59-70, doi: 10.1007/s10950-010-9207-6.

Teves-Costa, P., I. Almeida, R. Matildes, and I. Rodrigues (2010). Methodologies for $V_{S 30}$ estimation-Applications to Lisbon and Lower Tagus Valley region, in AGU Fall Meeting, San Francisco, California, NH31B-1358.

Victor, L. M., A. Hirn, and J. Veinante (1980). A seismic section across the Tagus Valley, Portugal—Possible evolution of the crust, Annales de Geophysique 36, 469-476.

Vilanova, S. P., and J. F. B. D. Fonseca (2007). Probabilistic seismic-hazard assessment for Portugal, Bull. Seismol. Soc. Am. 97, no. 5, 1702-1717, doi: 10.1785/0120050198.

Villaseñor, A., Y. Yang, M. H. Ritzwoller, and J. Gallart (2007). Ambient noise surface wave tomography of the Iberian Peninsula: Implications for shallow seismic structure, Geophys. Res. Lett. 34, no. 11, doi: 10.1029/2007GL030164.

Wald, D. J., and T. I. Allen (2007). Topographic slope as a proxy for seismic site conditions and amplification, Bull. Seismol. Soc. Am. 97, no. 5, 1379-1395, doi: 10.1785/0120060267.

Webb, S. C. (1998). Broadband seismology and noise under the ocean, Rev. Geophys. 36, no. 1, 105-142, doi: 10.1029/97RG02287.

Webb, S. C. (2007). The Earth's 'hum' is driven by ocean waves over the continental shelves, Nature 445, no. 7129, 754-756, doi: 10.1038/ nature05536.

Wessel, P., and W. H. F. Smith (1998). New, improved version of Generic Mapping Tools released, Eos Trans. AGU 79, no. 47, 579-579, doi: 10.1029/98EO00426.

Wilson, D., J. Leon, R. Aster, J. Ni, J. Schlue, S. Grand, S. Semken, S. Baldridge, and W. Gao (2002). Broadband seismic background noise at temporary seismic stations observed on a regional scale in the southwestern United States, Bull. Seismol. Soc. Am. 92, no. 8, 3335-3342, doi: 10.1785/0120010234

Zürn, W., and R. Widmer (1995). On noise reduction in vertical seismic records below $2 \mathrm{mHz}$ using local barometric pressure, Geophys. Res. Lett. 22, no. 24, 3537-3540, doi: 10.1029/95GL03369. 
Instituto Dom Luiz

Faculdade de Ciências

Universidade de Lisboa

Campo Grande, Ed. C8, Piso 3, Gab. 5

1749-016 Lisboa, Portugal

susanacustodio@campus.ul.pt

ccorela@fc.ul.pt

Immatias@fc.ul.p

(S.C., C.C., L.M.)

Instituto Superior de Engenharia de Lisboa

Rua Conselheiro Emídio Navarro, 1

1959-007 Lisbon, Portugal

ndias@adf.isel.pt

(N.A.D.)

Centro de Geof'sica de Évora e Departamento de Física ECT, Colégio Luís António Verney

Rua Romão Ramalho, 59

7000 Évora, Portugal

bafcc@uevora.pt

(B.C.)

Instituto Português do Mar e da Atmosfera, I.P.

Divisão de Geofísica

Rua $\mathrm{C}$ ao Aeroporto

1749-077 Lisboa, Portugal

fernando.carrilho@ipma.pt

madureiraguilherme@gmail.com

(F.C., G.M.)
Centro de Geofísica

Observatório Astronómico de Coimbra

Universidade de Coimbra

3040-004 Coimbra, Portugal

sara.carvalho@uc.pt

(S.C.)

Institut de Ciències de la Terra Jaume Almera

Consejo Superior de Investigaciones Científicas

C/ Lluis Solé Sabaris s/n

Barcelona E-08028, Spain

jdiaz@ictja.csic.es

(J.D.)

Instituto Superior Técnico

Av. Rovisco Pais, 1

1049-001 Lisboa, Portugal

JNUC55@gmail.com

(J.N.)

Helmholtz-Zentrum Potsdam

Deutsches GeoForschungsZentrum GFZ

Telegrafenberg (E323)

D-14473 Potsdam, Germany

haber@gfz-potsdam.de

(C.H.)
Manuscript received 27 March 2014;

Published Online 7 October 2014 